\title{
DAILY ACTIVITY PATTERNS OF LARGE AND MEDIUM-SIZED MAMMALS BASED ON CAMERA TRAPS DATA IN THE CENTRAL FOREST NATURE RESERVE, VALDAI UPLAND, RUSSIA
}

\author{
Sergey S. Ogurtsov ${ }^{1}$, Anatoliy S. Zheltukhin ${ }^{1}$, Ivan P. Kotlov ${ }^{2}$ \\ ${ }^{1}$ Central Forest State Nature Biosphere Reserve, Russia \\ ${ }^{2} A$.N. Severtsov Institute of Ecology and Evolution of RAS, Russia \\ e-mail:etundra@mail.ru,azheltukhin@mail.ru,ikotlov@gmail.com
}

Received: 12.02 .2018

\begin{abstract}
Here are presented the results of the analysis of daily activity patterns obtained from the data of camera traps for five large mammals (elk Alces alces, wild boar Sus scrofa, brown bear Ursus arctos, grey wolf Canis lupus, Eurasian lynx Lynx lynx) and three medium ones (European badger Meles meles, raccoon dog Nyctereutes procyonoides, mountain hare Lepus timidus) for the territory of the Central Forest Nature Reserve, Valdai Upland, Russia. Data were collected in the period 2010-2017 and the trap effort was 30158 camera days from 21 locations. Most of the mammals surveyed showed activity at night and twilight hours ( $71 \%$ of the pictures). The hare was most active among all and dominant at night. In many respects it is similar to the activity of a raccoon dog, which type can be defined as nocturnal too. Unlike a hare, a raccoon dog has a weak peak in the daytime and less activity in the night. Badgers movements are confined to the twilight and nighttime. The share of nocturnal activity of large ungulates such as elk and wild boar was approximately the same and amounted to about $45 \%$ of all registrations. The wild boar is slightly more active during the day and in the evening and is not active at all in the morning. The elk is active in the morning, and in the daytime and to a lesser extent in the evening. The lynx and the bear have similar cathemeral activity patterns: almost half of all their meetings occurred at daylight hours and only slightly - less than $40 \%$ - at night. The brown bear had the maximum number of registrations in the daytime among all the studied species. Despite the fact that the main object of lynx feeding in the reserve is the hare, there was no high degree of overlap between them $\left(\widehat{\Delta}_{4}=0.75\right)$. In the group of large carnivores, the wolf was noticeably distinguished, more than half of its registrations were at night, and a third - on daytime. Daily activities of the wolf and its main prey elk showed a large overlap $\left(\widehat{\Delta}_{4}=0.89\right)$. The seasonal variations of daily activity of all species were also shown. According to the results of factor analysis, each of the studied species was divided into one of three separate groups. The first group included species with a tendency to nocturnal activity (wolf, elk, hare, badger, and raccoon dog), the second group - cathemeral animals (bear and lynx). In the third group was only the wild boar, whose activity was associated with the evening hours. This is the first long-term continuous camera trap survey in Russia and it provides detailed daily activity patterns for multiple large and medium-sized sympatric mammals.
\end{abstract}

Key words: activity patterns, camera traps, Central Forest Nature Reserve, daily activity, large carnivores, noninvasive methods

\section{Introduction}

The study of the animal activity patterns is an important area of the science of their behaviour (Sokolov \& Kuznetsov, 1978; Munro et al., 2006; Yamazaki et al., 2008; Bridges \& Noss, 2011; Schai-Braun et al., 2012; Podolski et al., 2013; Lendrum et al., 2017). Temporal activity models are one of the main components of the general models of space and time use by species and, thus, represent an important aspect of the ecological niche of the organism (Roth \& Huber, 1986). The theory of optimality assumes that animals provide their well-being, constantly choosing between the available resource and the physiological losses spent for its consumption, as well as the potential risk of being killed (MacArthur \& Pianka,
1966; Schoener, 1971). Animal activity associated with the search for resources or a partner includes physiological costs and the risk of being eaten, and hence the activity models are consistent with the indicated theory (Bridges et al., 2004).

To date, there are several ways to study the activity of animals. Over the years, the only one was direct visual observation (Stelmock \& Dean, 1986; Koprowski \& Corse, 2005). The radio-collar method has become popular since 1980s, as well as GPS telemetry later (Roth \& Huber, 1986; Pépin \& Cargnelutti, 1994; Munro et al., 2006; Kolbe \& Squires, 2007; Yamazaki et al., 2008; Seryodkin et al., 2013; Zaccaroni et al., 2013). For forest-covered and impassable territories of many Russian nature reserves, the most optimal solution is the use 
of camera traps. This is an effective and accessible tool to study the behaviour and activity of mammals, already tested for many species in the world (Carthew \& Slater, 1991; Alexy et al., 2003; Bridges et al., 2004; Claridge et al., 2004; Bridges \& Noss, 2011; Crowley et al., 2013; Ikeda et al., 2016; Marcon et al., 2017). For the last ten years camera traps have become widely used in Russia (Rozhnov et al., 2012; Soutyrina et al., 2013; Matyukhina et al., 2016; Ogurtsov \& Zheltukhin, 2017; Zaumyslova \& Bondarchuk, 2017), but detailed studies of daily activity based on this method are known so far only for badgers (Meles sp.) (Sidorchuk \& Rozhnov, 2010; Sidorchuk et al., 2014, 2016).

Since the camera traps allow studying the diel rhythms of the majority of animals in the study area, regardless of the possibility of capturing them, this method more closely approximates the researcher to the population level of study than visual observations or telemetry (Bridges et al., 2004). Nevertheless camera traps do not provide comprehensive information on daily activity patterns, and the results obtained this way can only reflect the activity of animal movements within the locations of cameras. However, under a long period of research and even coverage of the territory, it is possible to obtain representative data accurately reflecting the diel rhythms of animals.

With the help of camera traps, various activities on this topic were organised. For example, comparative assessments of the temporal activity of the jaguar (Panthera onca L.), puma (Puma concolor L.) and their victims (Weckel et al., 2006; Romero-Muñoz et al., 2010; Foster et al., 2013; Hernández-SaintMartín et al., 2013), ocelot (Leopardus pardalis L.) and its victims (Di Bitetti et al., 2006; Porfirio et al., 2016). Data on the activity of carrion visiting by predators and vultures were obtained (López González \& Lorenzana Piña, 2002). Daily activity was revealed for large felines of Malaysia (Mohd-Azlan \& Sharma, 2006) and black bears (Ursus americanus Pallas) in the USA (Bridges et al., 2004). A number of surveys on daily activity of various animals were carried out in the rain forests of Bolivia, where the camera traps were located on roads and trails (Gómez et al., 2005; Maffei et al., 2007). Studies have been conducted which investigate the influence of anthropogenic factor on the daily rhythms of small, medium and large mammals (Lendrum et al., 2017). The studies of daily activities of sympatric mammalian species using camera traps have been carried out in Taiwan (Chen et al., 2009), Madagascar (Gerber et al., 2012), Northern
Japan (Ikeda et al., 2016), South-west China (Bu et al., 2016) and Romania (Marcon et al., 2017).

Most of the camera trap studies are constricted by a short time period or small trap effort, but there are few long-term surveys, which can provide data for the construction of sustainable activity patterns of the different species of mammals. Besides, most of these studies are devoted more to tropical mammals than to boreal and especially European.

This study is the first long-term continuous camera trap survey in Russia and it provides detailed daily activity patterns for multiple large and medium-sized sympatric mammals. The objectives of this study were to: 1) determine the daily activity patterns of each species; 2) detect changes in daily activity patterns among seasons; 3 ) quantify the temporal overlap between species; 4) identify groups of species by the similarity in their daily activity patterns.

\section{Study area}

The works were carried out on the territory of the Central Forest State Nature Biosphere Reserve (CFNR, Tver region, Russian Federation). The reserve is located in western European Russia in the immediate watershed of the upper Volga and Zapadnaya (West) Dvina rivers at the southwestern edge of the Valdai Upland $\left(56^{\circ} 26^{\prime}-56^{\circ} 31^{\prime} \mathrm{N}\right.$ and $\left.32^{\circ} 29^{\prime}-33^{\circ} 01^{\prime} \mathrm{E}\right)$. The area of the reserve is 244.15 $\mathrm{km}^{2}$ and the protected zone around it is 460.61 $\mathrm{km}^{2}$. The territory is characterised by a temperate moderately continental climate with relatively cold winters and warm summers. More than half of the precipitation falls as rain in the summer-autumn period and the rest is falling as snow during winter-spring (Olchev et al., 2017). The mean air temperature of the study area is $+4.21^{\circ} \mathrm{C}\left(+16^{\circ} \mathrm{C}\right.$ in July and $-10^{\circ} \mathrm{C}$ in January). The mean annual precipitation is $730.9 \mathrm{~mm}$. The amplitude of altitudes is $72.4 \mathrm{~m}$ at a mean altitude of $246 \mathrm{~m}$ a.s.1. (Puzachenko et al., 2016).

The flora of the reserve is typical European and relatively poor as compared to the flora of other forested territories. The forest flora is mainly composed of a boreal group of species widespread in the taiga zone with spruce (Picea abies (L.) H. Karst.) dominating and species of the nemoral group such as tillet (Tilia cordata Mill.), hazel (Corylus avellana L.), elm (Ulmus glabra Huds. and Ulmus laevis Pall.). Aspen (Populus tremula L.), birch (Betula spp.), gray alder (Alnus incana (L.) Moench), and black alder (Alnus glutinosa (L.) Gaertn.) usually 
predominate on the disturbed areas after windfalls or clearings (in the past). A special place in the landscape cover belongs to raised bogs which occupy over $7 \%$ of the territory and the pine (Pinus sylvestris L.) bog forests. In the territory of the reserve the croplands were abandoned more than 100 years ago. At the present time, spruce forests occupy them. Nowadays, rich forb meadows located on the place of the croplands and hayfields. They are gradually displacing by shrubs and birch. The fauna of CFNR is of European origin, but it includes striking Siberian representatives, the distribution of which in Europe is usually related to boreal taiga landscapes. It represents a complex of nemoral species of broadleaved forests and taiga (Puzachenko et al., 2016). Only one populated area is situated near the reserve border - Zapovedniy village, where the administration of the reserve is located.

The Central Forest Nature Reserve is the greatest massif in European Russia of rare, old spruce forests. The combination of old spruce forests with large undisturbed raised bogs, secondary forests at different stages of regeneration on felled areas, fallow fields and meadows determine a high level of landscape diversity and create unique possibilities for studying the natural processes.

\section{Data collection}

In this study totally 25 cameras were used during the period of 2010-2017. Reconyx RapidFire RC60 and HyperFire HC600 models (Reconyx ${ }^{\circledR}$ ) were used, which have the ability to shoot in infrared band (PIR). Each camera trap was placed on the location with a permanent unique number. Data were processed only from those locations where the devices functioned successfully for more than 1 year (21 locations). The installation of the camera traps and their maintenance were carried out according to protocols for monitoring studies (Brown \& Gehrt, 2009; Mohamad \& Darmaraj, 2009; TEAM Network, 2011; Meek et al., 2012). Material and data were presented according to general recommendations for camera trapping studies (Meek et al., 2014). All camera traps were located in the southern forestry of the reserve in a spruce and leaf-spruce forest types on a permanent route of mammal activity tracking which length is about $30 \mathrm{~km}$ (Fig. 1). The average distance between locations was $1.2 \mathrm{~km}(0.7-2.2 \mathrm{~km}$; $\mathrm{SD}=0.37)$. The effectively covered area was $54.5 \mathrm{~km}^{2}$ (calculated as buffer polygon with radius $1.2 \mathrm{~km}$ around each location). The layout of the cameras was mostly deliberately-biased; all devices were located on for- est roads, mutually intersecting glades and animal tracks. Camera traps were fixed on tree trunks at a height of $60 \mathrm{~cm}$ to $120 \mathrm{~cm}$ at some angle to the surface of the earth. The distance from them to the forest road or trail was 4-5 $\mathrm{m}$. In summer, the space in front of the camera was released from the shrubbery, high grassy vegetation and objects capable of interfering with the quality of shooting of passing animals. No scent lure or another attractant was applied. Since activation, the camera traps have been in the working mode throughout the research period and programmed to operate for 24 hours/day. Before work, all devices were set to shoot a series of five frames for each moment of motion fixation. The shooting sensitivity was set to the maximum; the trigger interval was set as $1 \mathrm{sec}$. One registration case (trap event) equals the passage of individuals of one species along the camera trap, regardless of the number of frames and the time spent on the location. To avoid autocorrelation and to minimise the incidence of multiple shots, we only used photos taken at least 1 hour apart for each species, unless it was possible to distinguish individuals, in which case each event was considered independently (Di Bitetti et al., 2006; Lucherini et al., 2009; RomeroMuñoz et al., 2010; Foster et al., 2013).

\section{Data analysis}

The initial material for the analysis was the resulting photographs in JPG format. The unloading, storage, sorting and initial processing of images were carried out with the help of Reconyx software - MapView Professional v.3.4 (Reconyx, Inc.). The main performance indicators for camera traps are standard for this kind of research (Mohd-Azlan \& Sharma, 2006; Kelly \& Holub, 2008; Rovero et al., 2014). These include the number of trap nights (or camera days) spent by one camera at $i$-th location (TN); number of animal passes/registrations (TE - trap events) at $i$-th location; total number of pictures/frames for each species; the relative abundance index (RAI or TS - trap success), which was calculated by formula:

$$
R A I=\left(\sum_{i=1} T E_{i} / \sum_{i=1} T N_{i}\right) * 100
$$

It should be noted that firmware update with the new version from the manufacturer should be done periodically. Some devices failed to record time-of-day meta-information (a.m. instead of p.m. time), which completely distorted the activity data. All such photographs were checked manually and corrected. After the firmware update, such problems, as a rule, disappeared. 

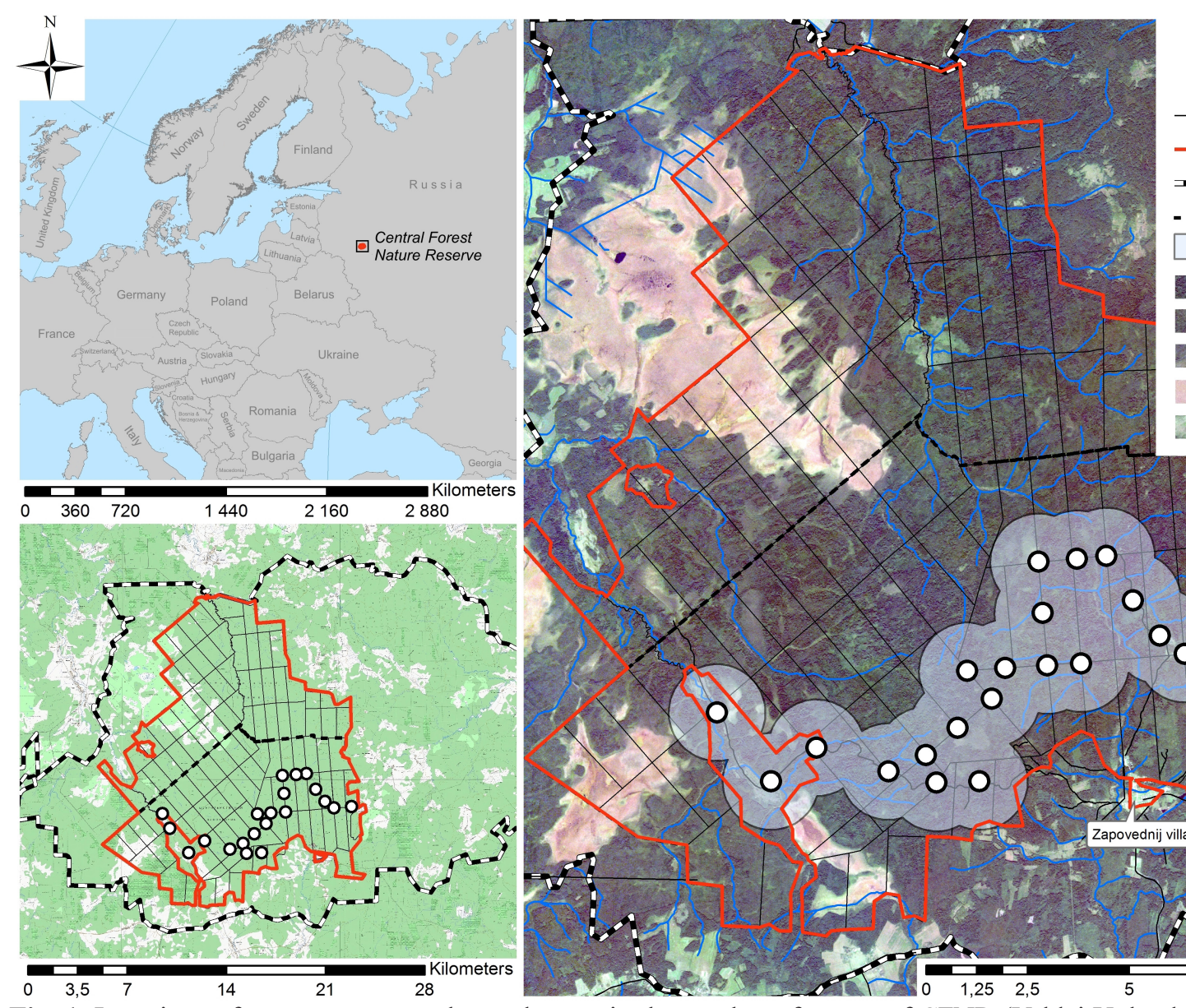

\section{Legend}

Camera trap location

Glades, forest roads

Reserve border

-... Protected zone border

- - - - Forestry border

Covered area Spruce and leaf-spruce
forest Secondary leaf forest

P. Pine bog forest

Raised bog

21. Rural area, cuts,

Fig. 1. Locations of camera traps on the study area in the southern forestry of CFNR (Valdai Upland, Russia) for the study period of 2010-2017. Main map based on RapidEye 5 satellite image.

Eight background species of mammals were selected as model ones, the success of capturing them with camera traps (RAI) exceeds 1 . The exception was the European badger (Meles meles L.) whose activity was confined to burrows and individual sites around them. Five species belong to Carnivora: grey wolf (Canis lupus L.), Eurasian lynx (Lynx lynx L.), brown bear (Ursus arctos L.), raccoon dog (Nyctereutes procyonoides Gray), and European badger; two species belong to Artiodactyla: elk (Alces alces L.) and wild boar (Sus scro$f a$ L.); and one Lagomorpha species - mountain hare (Lepus timidus L.) (Table 1, Fig. 2). By size, five species are classified as large (elk, wild boar, brown bear, wolf, lynx) and three are as mediumsized mammals (badger, raccoon dog, hare).

Each day was divided into three periods: daytime, nighttime and twilight. The duration of these periods is different for various authors. Some take a twilight time interval with the duration of 120 minutes before and after sunrise and sunset, respectively (Bridges et al., 2004) or 60 minutes as well (Romero-Muñoz et al., 2010; Gerber et al., 2012; Ross et al., 2013; Ikeda et al., 2016). Others consider under twilight the time from morning twilight to sunrise and from sunset to evening twilight, defining the period between sunrise and sunset as daytime (Munro et al., 2006). There are studies where the duration of the periods was limited to strict time frames, for example, the night activity was determined by the interval from 19:00 to 5:00 (Mohd-Azlan \& Sharma, 2006; Ross et al., 2013), and there are those where only day and night intervals were taken (Yamazaki et al., 2008). In our case, the periods were determined by the time of sunrise and sunset for each date that were calculated for the geographic coordinates of the reserve $\left(32^{\circ} 58^{\prime} \mathrm{E}, 56^{\circ} 27^{\prime} \mathrm{N}\right.$, GMT +3) using the website www.sunrisesunset.com. We used four intervals: morning twilight (time $1 \mathrm{~h}$ before and after sunrise), daytime (time between the end of the morning twilight and the start of the evening twilight), evening twilight (time $1 \mathrm{~h}$ before and after sunset) and night (time between the end of the evening twilight and the start of the morning twilight). Further, twilights were pooled together in one period. Seasons were divided on four periods according to climatic data from weather station of the reserve, and were determined by average temperatures for each period and year. Average dates for seasons were as follow: for winter - 06.11-08.03; spring - 09.03-16.05; summer-17.05-25.08; autumn - 26.08-05.11. 


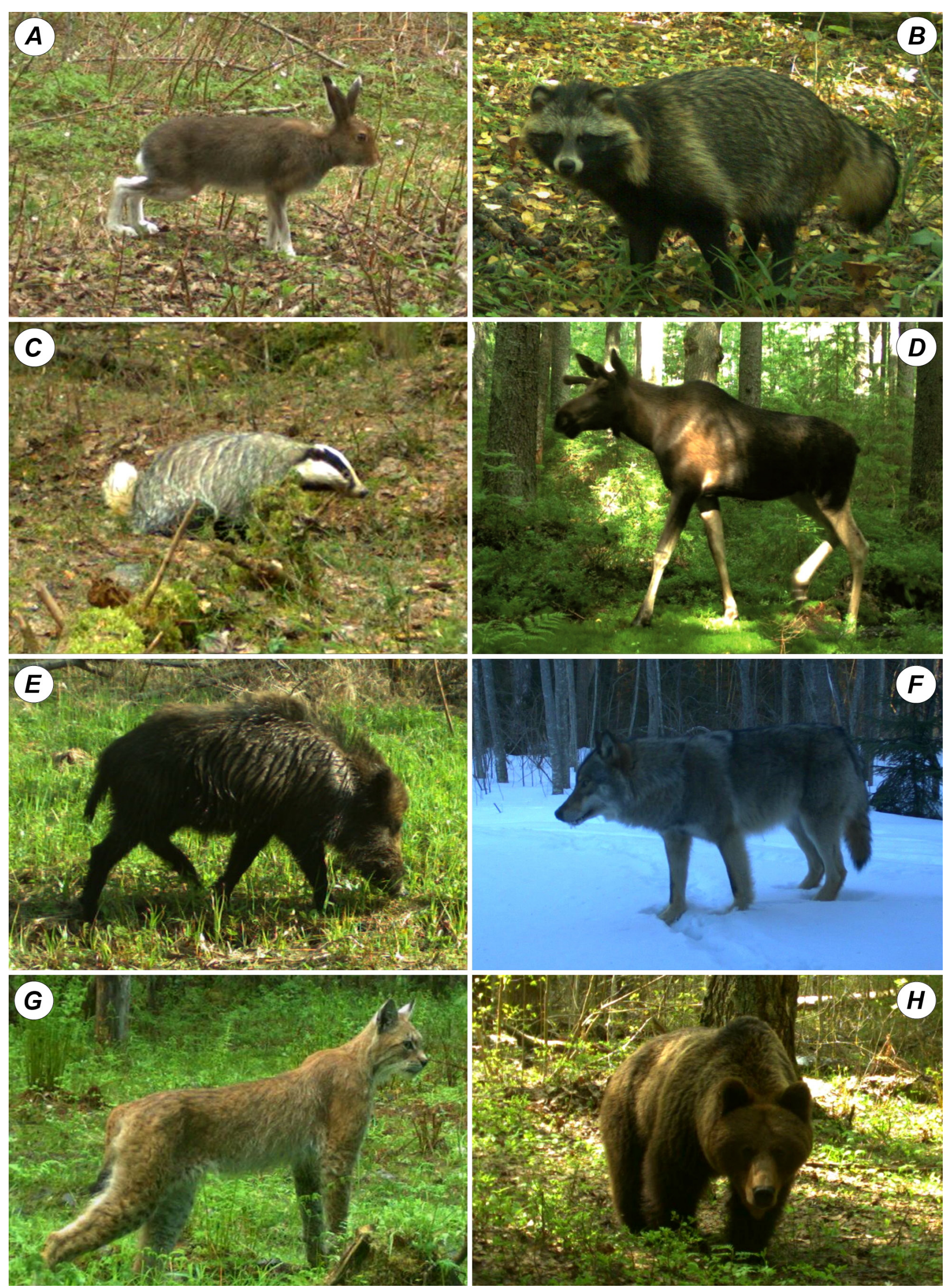

Fig. 2. Camera trap photos of model mammal species in the study on daily activity patterns in the CFNR in $2010-2017$. $A$ - mountain hare (Lepus timidus); $B$ - raccoon dog (Nyctereutes procyonoides); $C$ - European badger (Meles meles); D elk (Alces alces); E - wild boar (Sus scrofa); F- grey wolf (Canis lupus); G - Eurasian lynx (Lynx lynx); H - brown bear (Ursus arctos). Photos from camera traps. 
Table 1. The results of the work of camera traps on 21 locations for eight mammal species in the CFNR in 2010-2017

\begin{tabular}{|l|c|c|c|c|}
\hline \multicolumn{1}{|c|}{ Animal species } & TE & RAI & Number of pictures & \% of pictures \\
\hline Mountain hare (Lepus timidus) & 814 & 2.70 & 4605 & 14.69 \\
\hline Raccoon dog (Nyctereutes procyonoides) & 406 & 1.35 & 2459 & 7.85 \\
\hline European badger (Meles meles) & 124 & 0.41 & 734 & 2.34 \\
\hline Elk (Alces alces) & 494 & 1.64 & 7125 & 22.73 \\
\hline Wild boar (Sus scrofa) & 301 & 1.00 & 5785 & 18.46 \\
\hline Grey wolf (Canis lupus) & 434 & 1.44 & 3767 & 12.02 \\
\hline Eurasian lynx (Lynx lynx) & 343 & 1.14 & 2227 & 7.11 \\
\hline Brown bear (Ursus arctos) & 649 & 2.15 & 4634 & 14.78 \\
\hline Total & 3565 & - & 31345 & 100 \\
\hline
\end{tabular}

To observe if species' activity was predominately categorised as crepuscular, diurnal, nocturnal or cathemeral, we calculated selection ratios of use to availability to each time period by each species following Manly et al. (2002) by the formula:

$$
w_{i}=o_{i} / \pi_{i}
$$

$w_{i}$ is the selection ratio for the period $i ; \mathrm{o}_{i}$ is proportion of trap events in period $i ; \pi_{i}$ is proportions of length in period $i$ to the length of all periods. $w_{i}>1$ indicates that the time period is selectively used more than availability; $w_{i}<1$ indicates the time period is avoided (Gerber et al., 2012; Bu et al., 2016).

Like in many other similar studies we used the approach developed by Ridout \& Linkie (2009) to estimate the activity patterns of each species using kernel density analysis (Foster et al., 2013; Ross et al., 2013; Bu et al., 2016; Ikeda et al., 2016; Porfirio et al., 2016; Marcon et al., 2017). This is a non-parametric method for evaluating the probability density function of a random variable (Worton, 1989), time of capture in our case. We measured the overlap between the two estimated distributions using a coefficient of overlapping $\Delta$, which varies from 0 (no overlap), to 1 (complete overlap) (Ridout \& Linkie, 2009). The coefficient is defined as the area under the curve which is formed by taking the minimum of the two density functions at each time point (Linkie $\&$ Ridout, 2011). Because all our samples were more than 50 we used Dhat 4 estimator (Meredith \& Ridout, 2017). The $95 \%$ confidence intervals (CI) of the overlap were obtained by 10000 bootstrap samples from the estimated probability density functions of each species. All these procedures were implemented in R 3.3.1 software (R Development Core Team, 2015) with the «camtrapR» (Niedballa et al., 2016) and «overlap» (Meredith \& Ridout, 2017) packages.

Activity data present a circular distribution, so we compared the distributions of several samples of activity patterns among seasons using the non- parametric Watson-Wheeler test of homogeneity of means (Zar, 2010). This test indicates if there is a significant statistic difference between circular distributions, and it has been used to analysed data from 24 hours activity patterns (Romero-Muñoz et al., 2010; Hernández-SaintMartín et al., 2013; Porfirio et al., 2016). We used R package «circular» for this (Lund et al., 2017). To check the differences in records and RAI among time periods and seasons the $\chi^{2}$-test was implemented. For seasonal variation estimates we only used data from 20132017 because of the low number of locations and small trap effort till 2013. For combination species into groups such as nocturnal, diurnal, crepuscular, and cathemeral animals, we used the factor analysis. All these procedures were performed in the Statistica 8.0 software (StatSoft, Inc.). Statistical significance was set at 0.05 . Mapping procedures were performed in ArcMap 10.4 (Esri Inc.).

All animals registered by the camera traps were in motion for the vast majority of cases. Although various elements of the basic forms of behaviour were recorded at the same time, they generally characterise the locomotor activity. Accordingly, in this work, the term "daily activity» considers exclusively the locomotor activity of animals recorded by camera traps during the day.

\section{Results}

During the 8-year period, 30158 trap nights were processed, 33578 images with wild animals from 21 locations were obtained. The processing received 31345 images of the studied mammals, which make $93.35 \%$ of all photos of wild animals. Most images were taken from the elk $(22.73 \%)$, wild boar (18.46\%), brown bear (14.78\%) and hare $(14.69 \%)$, while the total share of photos of all large carnivores (wolf, lynx and bear) was $33.91 \%$ (Table 1). The maximum values of the abundance index were noted for the hare $(\mathrm{RAI}=2.70)$ and the brown bear $(\mathrm{RAI}=2.15)$. 


\section{Daily activity patterns}

The very first and general data on the activity of animals can be obtained yet from the statistics of the PIR sensor of cameras. Given the stable operation of this device and the recording of shooting information in the image metadata, it is possible to accept with some error the mode of its active operation (in case of lack of lighting) for night and twilight, and the passive mode for daytime. Thus, 1044 registrations (29\%) were in the daytime and $2521(71 \%)$ - at dusk and at night.

A high night activity was observed for the badger $(69.35 \%$ of registrations), hare $(68.92 \%)$ and raccoon $\operatorname{dog}(64.04 \%)$, i.e. for representatives of the medium-sized class (Table 2). All these species had a high Manly selection ratio for nighttime $\left(w_{i}>1.5\right)$ and can be categorised as nocturnal. The activity of the hare during the night hours did not differ significantly from that of the badger, and the raccoon $\operatorname{dog}\left(\chi^{2}=2.8, \mathrm{p}=\right.$ $0.25)$. For the hare and badger also twilight period was preferred $\left(w_{i}>1.1\right)$. For large ungulates such as elk and wild boar, the share of daytime activity was approximately the same and amounted to about $30 \%$ of all registrations. The difference between them was that the elk had mostly crepuscular activity $\left(w_{i}=1.71\right)$. On the contrary, the wild boar was equally active in the night and twilight $\left(w_{i}=1.2\right.$ for each period). In the group of large carnivores, the rhythm of daily activity was markedly distinguished by the wolf, more than half of its registrations were at night (almost 54\%, $w_{i}=$ 1.33), and a third - on the day. The lynx and the brown bear had similar diurnal registrations: almost $40 \%$ of all their passes through the camera traps occurred at daylight and approximately $35 \%$ - in the dark. The total share of twilight hours of the lynx's activity was higher and was $25 \%\left(w_{i}=\right.$ 1.46), while that of the bear was $22 \%\left(w_{i}=1.33\right)$, but they did not differ significantly. The brown bear had the largest part of registrations in the daytime of all the studied animals (44\%). Bear and lynx were the only species that had no significance differences throughout the day and may be classified as cathemeral.

Considering the day as a period of 24 hours it is possible to present activity patterns in the form of density plots (Fig. 3). The data presented on the plots reflect the same tendencies as the activity considered by the periods of the day, but allow us to notice both the extremums of values and certain subtle features. For example, a sharp decline in the activity of the wolf occurred at 2 a.m. The minimum activity was at 2 p.m., i.e. exactly 12 hours later. In this case, it is possible to talk about the rhythm of a decrease in activity with a cycle of half a day. The elk had an almost identical pattern with the recessions at $1 \mathrm{a} . \mathrm{m}$. and $12 \mathrm{a} . \mathrm{m}$. The percentage of daily activity for elk and wild boar was similar, but its dynamics by the hours was different. The plots show the prevalence of afternoon registrations of wild boar $(25 \%$ of observation between 12 a.m. and 6 p.m.) over elk (13\%). The hourly activity of the lynx and the bear on plots coincides with the percentage for the periods. The maximum decline for the bear was observed at 12 a.m., while for the lynx at 3 p.m.

The proportions of morning registrations of the hare and raccoon dog did not differ significantly; however, the hare used the time period from 6 a.m. to 8 a.m. more than the raccoon $\operatorname{dog}(9 \%$ and $3 \%$ of observations respectively). The raccoon dog used the first half of the day from sunrise to noon less than from noon to sunset (10 and $17 \%$ of observations respectively), like the badger ( 3 and $6 \%$ ). In the hare the proportions of these periods were different (11 and 9\%), i.e. it was a little bit more inclined to morning activity.

Table 2. Frequency of registrations (TE, \%) and Manly selection ratios $\left(w_{i}\right)$ throughout periods of the day for eight mammal species in the CFNR in 2010-2017

\begin{tabular}{|c|c|c|c|c|c|c|c|c|c|}
\hline \multirow{2}{*}{ Animal species } & \multicolumn{2}{|c|}{ Nighttime } & \multicolumn{2}{|c|}{ Daytime } & \multicolumn{2}{|c|}{ Twilight } & \multirow{2}{*}{ Category } & \multirow{2}{*}{$\chi^{2}$ value } & \multirow{2}{*}{$\mathrm{p}$} \\
\hline & TE, $\%$ & $w_{i}$ & TE, $\%$ & $w_{i}$ & TE, $\%$ & $w_{i}$ & & & \\
\hline Mountain hare & 68.92 & 1.71 & 11.79 & 0.27 & 19.29 & 1.16 & $\mathrm{~N} / \mathrm{Cr}$ & 9.80 & $<0.05$ \\
\hline Raccoon dog & 64.04 & 1.59 & 24.63 & 0.57 & 11.33 & 0.68 & $\mathrm{~N}$ & 12.19 & $<0.05$ \\
\hline European badger & 69.35 & 1.72 & 10.48 & 0.24 & 20.16 & 1.21 & $\mathrm{~N} / \mathrm{Cr}$ & 8.40 & $<0.05$ \\
\hline Elk & 43.32 & 1.07 & 28.14 & 0.65 & 28.54 & 1.71 & $\mathrm{Cr} / \mathrm{N}$ & 11.40 & $<0.05$ \\
\hline Wild boar & 48.50 & 1.20 & 31.89 & 0.74 & 19.60 & 1.18 & $\mathrm{~N} / \mathrm{Cr}$ & 11.81 & $<0.05$ \\
\hline Grey wolf & 53.46 & 1.33 & 30.65 & 0.71 & 15.90 & 0.95 & $\mathrm{~N}$ & 10.52 & $<0.05$ \\
\hline Eurasian lynx & 37.90 & 0.94 & 37.61 & 0.88 & 24.49 & 1.46 & $\mathrm{Cr} / \mathrm{Ca}$ & 4.39 & 0.11 \\
\hline Brown bear & 34.05 & 0.84 & 43.76 & 1.02 & 22.19 & 1.33 & $\mathrm{Cr} / \mathrm{D}$ & 2.77 & 0.25 \\
\hline
\end{tabular}

Note: differences in TE among three time periods were tested by one-way ANOVA. D, N, Cr and Ca indicate diurnal, nocturnal, crepuscular and cathemeral activity, respectively. 

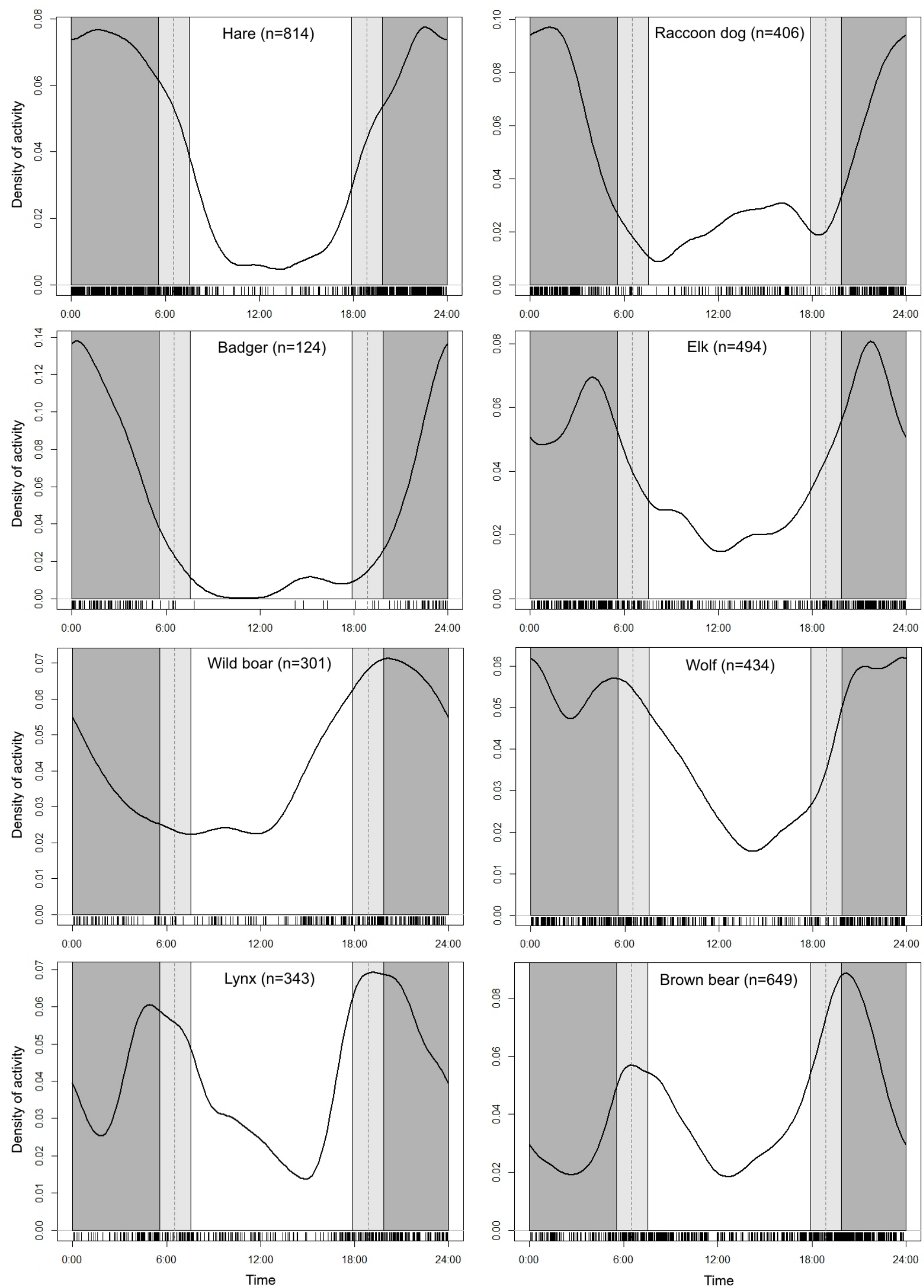

Fig. 3. Kernel densities of daily activity of eight mammal species (solid line) according to the data of camera traps in the CFNR in 2010-2017. Individual records (TE) are shown as short vertical lines above X-axis, dark grey shaded area, light grey shaded area and grey dashed lines represent the approximate nighttime, twilight periods and time of sunrise and sunset respectively. 
Some species had a unimodal type of activity (hare, badger, wild boar) with one peak. The raccoon dog had one expressed peak in the night and another smoothed after noon. The elk and wolf had a bimodal type, but both their peaks were close to each other in the nighttime and only the lynx and bear had a true bimodal type with high peaks in the morning and evening (Fig. 3).

Daily activity patterns among seasons of the year

Within a year the activity pattern of an animal can vary for various reasons. The differences may relate to both the level of activity (number of records in each period), and the time of activity (prevailing time of records in each period). The constructed kernel density plots of the activity of the species under consideration for four seasons allow one to visually assess the variability of the frequency of records at different times during the year (Fig. 4).

In the medium-sized mammal group during the year the activity pattern of the hare changed the most $(\mathrm{W}=57.06, \mathrm{p}<0.05$; hereinafter Watson-Wheeler test). The hare was nocturnal in the winter and spring, but in the spring it also had crepuscular activity. In summer the hare was cathemeral and in autumn it was crepuscular and nocturnal. During all seasons the activity levels changed significantly in all periods (Table 3 ). The raccoon dog remained mostly inactive in the winter season, falling into winter sleep. In other parts of the year its activity changed significantly (W
$=17.68, \mathrm{p}<0.05)$ and was strongly nocturnal except summer, when it showed mostly a cathemeral type (Fig. 4). Its level of activity significantly changed in daytime and nighttime (Table 3). In winter, also the badger was inactive, falling into hibernation. In spring, its activity increased sharply and was nocturnal. Throughout the seasons the badger was more of a nocturnal animal with a slight increase in the proportion of twilight activity in summer. In the autumn, its activity was sharply reduced and was confined almost entirely to nighttime (Fig. 4, Table 3). There were no significant differences in time of activity among seasons $(\mathrm{W}=0.45, \mathrm{p}=0.98)$. The levels of activity were stable except at nighttime, when activity increased sharply in spring and then declined $\left(\chi^{2}=\right.$ $8.28, \mathrm{p}<0.05)$.

In the group of ungulate animals there seemed to be a tendency to shift activity within the year (Table 4). The elk had differences in activities within the seasons $(\mathrm{W}=43.73, \mathrm{p}<0.05)$. It was nocturnal in winter, than diurnal in spring. In the summer period it had a cathemeral activity with big crepuscular part. The elk became nocturnal again in autumn, but more strongly than in winter. The wild boar was not characterised by such a strong change in its activity level during the year as the elk but it had a bigger shift in time of activity ( $\mathrm{W}=49.84, \mathrm{p}<0.05)$. It stayed mostly cathemeral in winter, clearly cathemeral in spring and then became diurnal in summer. In autumn it had a cathemeral activity with tendency to nighttime.

Table 3. Seasonal variations in daily activity patterns of medium-sized mammals (hare, raccoon dog, badger) in the CFNR in 2013-2017

\begin{tabular}{|c|c|c|c|c|c|c|c|c|c|c|}
\hline \multirow{2}{*}{\multicolumn{2}{|c|}{ Season }} & \multirow{2}{*}{\multicolumn{2}{|c|}{$\begin{array}{c}\text { Twilight } \\
\mathrm{M} \pm \mathrm{m}\end{array}$}} & \multirow{2}{*}{\multicolumn{2}{|c|}{$\begin{array}{c}\text { Daytime } \\
\mathrm{M} \pm \mathrm{m}\end{array}$}} & \multirow{2}{*}{\multicolumn{2}{|c|}{$\begin{array}{c}\text { Nighttime } \\
\mathrm{M} \pm \mathrm{m}\end{array}$}} & \multirow{2}{*}{ Category } & \multirow{2}{*}{$\chi^{2}$ value } & \multirow{2}{*}{$\mathrm{p}$} \\
\hline & & & & & & & & & & \\
\hline \multicolumn{11}{|c|}{ Mountain hare } \\
\hline \multicolumn{2}{|l|}{ Winter } & \multicolumn{2}{|c|}{$0.24 \pm 0.04$} & \multicolumn{2}{|c|}{$0.04 \pm 0.03$} & \multicolumn{2}{|c|}{$2.70 \pm 0.34$} & $\mathrm{~N}$ & 9.58 & $<0.05$ \\
\hline \multicolumn{2}{|l|}{ Spring } & \multicolumn{2}{|c|}{$1.09 \pm 0.24$} & \multicolumn{2}{|c|}{$0.60 \pm 0.14$} & \multicolumn{2}{|c|}{$3.95 \pm 0.62$} & $\mathrm{~N}$ & 9.58 & $<0.05$ \\
\hline \multicolumn{2}{|l|}{ Summer } & \multicolumn{2}{|c|}{$0.43 \pm 0.11$} & \multicolumn{2}{|c|}{$0.53 \pm 0.16$} & \multicolumn{2}{|c|}{$0.48 \pm 0.07$} & $\mathrm{Ca}$ & 0 & 1 \\
\hline \multicolumn{2}{|l|}{ Autumn } & \multicolumn{2}{|c|}{$0.61 \pm 0.17$} & \multicolumn{2}{|c|}{$0.05 \pm 0.02$} & \multicolumn{2}{|c|}{$0.78 \pm 0.13$} & $\mathrm{Cr} / \mathrm{N}$ & 7.60 & $<0.05$ \\
\hline$\chi^{2}$ value & $\mathrm{p}$ & 9.00 & $<0.05$ & 10.68 & $<0.05$ & 13.08 & $<0.05$ & & & \\
\hline \multicolumn{11}{|c|}{ Raccoon dog } \\
\hline \multicolumn{2}{|l|}{ Winter } & & & \multicolumn{2}{|c|}{$0.01 \pm 0.01$} & \multicolumn{2}{|c|}{$0.18 \pm 0.08$} & $\mathrm{~N}$ & 7.54 & $<0.05$ \\
\hline \multicolumn{2}{|l|}{ Spring } & \multicolumn{2}{|c|}{$0.12 \pm 0.05$} & \multicolumn{2}{|c|}{$0.19 \pm 0.14$} & \multicolumn{2}{|c|}{$0.88 \pm 0.39$} & $\mathrm{~N}$ & 7.90 & $<0.05$ \\
\hline \multicolumn{2}{|l|}{\begin{tabular}{|l|} 
Summer \\
\end{tabular}} & \multicolumn{2}{|c|}{$0.40 \pm 0.13$} & 0.63 & 0.24 & 1.29 & 0.46 & $\mathrm{Ca}$ & 4.80 & 0.09 \\
\hline Autumn & & 0.10 & 0.05 & 0.37 & 0.13 & 1.09 & 0.29 & $\mathrm{~N}$ & 10 & $<0.05$ \\
\hline$\chi^{2}$ value & $\mathrm{p}$ & 7.37 & 0.06 & 12.13 & $<0.05$ & 8.28 & $<0.05$ & & & \\
\hline & & & & & Europe & badge & & & & \\
\hline Winter & & & & & & 0.08 & 0.02 & - & - & - \\
\hline Spring & & 0.11 & 0.04 & 0.08 & 0.04 & 0.70 & 0.36 & $\mathrm{~N}$ & 6.86 & $<0.05$ \\
\hline Summer & & 0.19 & 0.08 & 0.10 & 0.07 & 0.46 & 0.18 & $\mathrm{~N}$ & 7.68 & $<0.05$ \\
\hline Autumn & & 0.02 & 0.02 & & & 0.10 & 0.02 & $\mathrm{~N}$ & 8.40 & $<0.05$ \\
\hline$\chi^{2}$ value & $\mathrm{p}$ & 6.93 & 0.07 & 6.25 & 0.10 & 8.28 & $<0.05$ & & & \\
\hline
\end{tabular}

Note: values indicate average RAI and its error of mean. Differences in RAI among three time periods and seasons were tested by one-way ANOVA, main activity were categorised by Manly selection ratio. D, N, Cr and Ca indicate diurnal, nocturnal, crepuscular and cathemeral activity, respectively. 

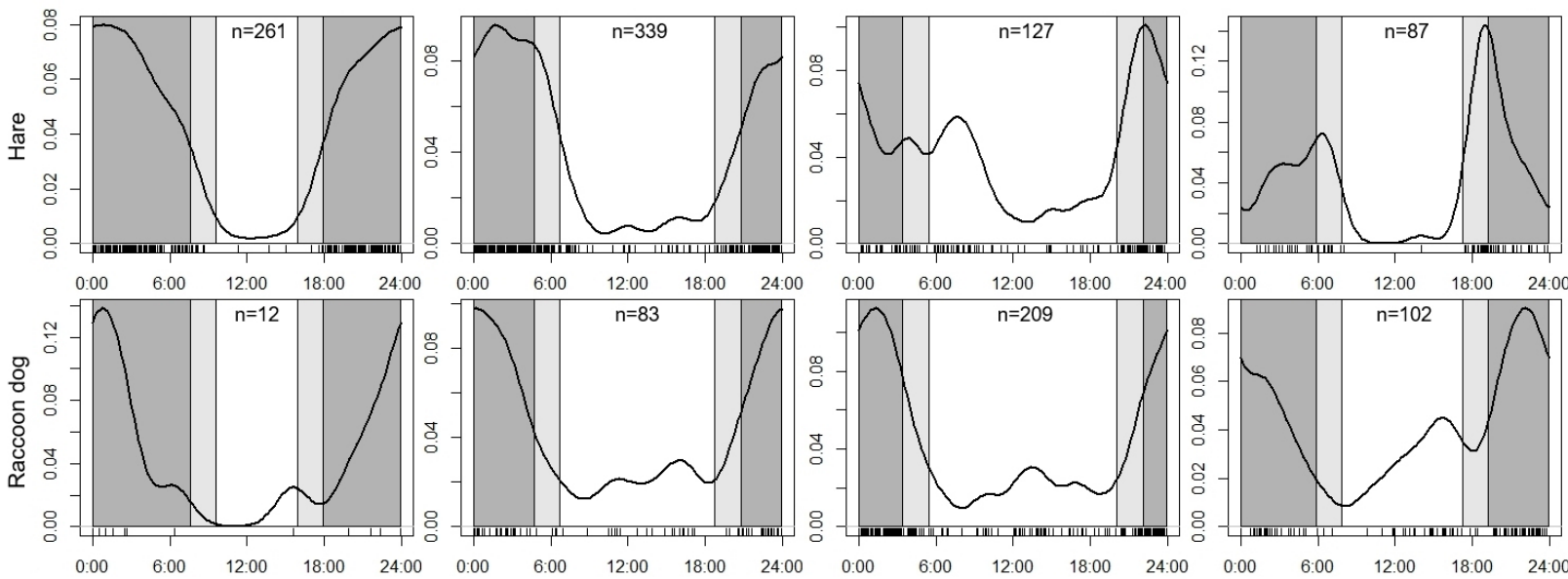

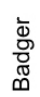
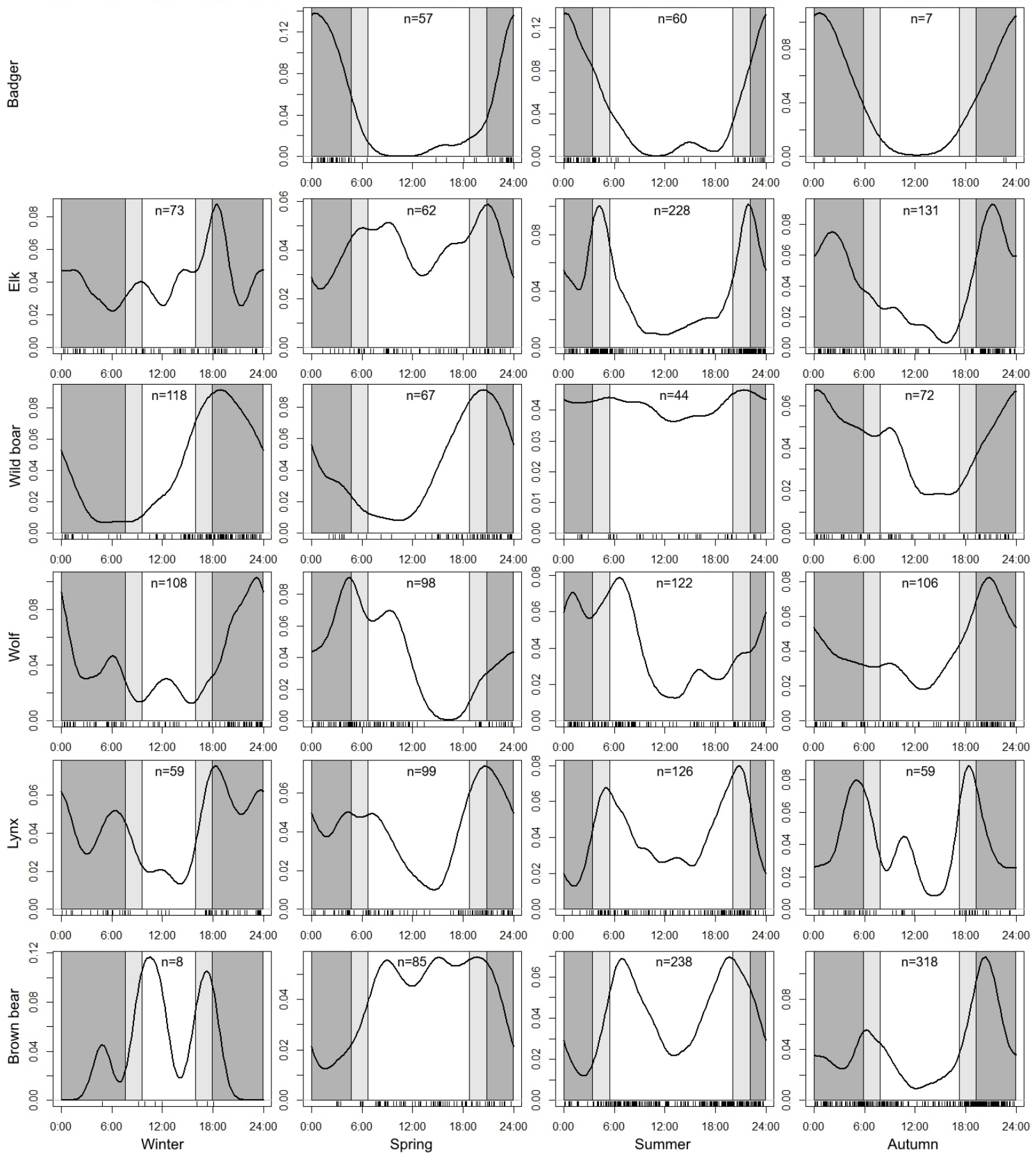

Fig. 4. Seasonal patterns of daily activity of eight mammal species in the CFNR in 2010-2017. Black lines and bars, dark grey and light grey shaded areas indicate kernel densities and trap events, night-time and twilight periods respectively; $\mathrm{x}$-axis - time in hours, y-axis - density of activity. 
Table 4. Seasonal variations in daily activity patterns of ungulates (elk, wild boar) in the CFNR in 2013-2017

\begin{tabular}{|c|c|c|c|c|c|c|c|c|c|c|}
\hline \multirow{2}{*}{\multicolumn{2}{|c|}{ Season }} & \multirow{2}{*}{\multicolumn{2}{|c|}{$\begin{array}{c}\text { Twilight } \\
\mathrm{M} \pm \mathrm{m}\end{array}$}} & \multirow{2}{*}{\multicolumn{2}{|c|}{$\begin{array}{c}\text { Daytime } \\
\mathrm{M} \pm \mathrm{m}\end{array}$}} & \multirow{2}{*}{\multicolumn{2}{|c|}{$\begin{array}{c}\text { Nighttime } \\
\mathrm{M} \pm \mathrm{m}\end{array}$}} & \multirow{2}{*}{ Category } & \multirow{2}{*}{$\chi^{2}$ value } & \multirow{2}{*}{$\mathrm{p}$} \\
\hline & & & & & & & & & & \\
\hline \multicolumn{11}{|c|}{ Elk } \\
\hline \multicolumn{2}{|l|}{ Winter } & \multicolumn{2}{|c|}{$0.17 \pm 0.05$} & \multicolumn{2}{|c|}{$0.15 \pm 0.03$} & \multicolumn{2}{|c|}{$0.58 \pm 0.11$} & $\mathrm{~N}$ & 8.32 & $<0.05$ \\
\hline \multicolumn{2}{|l|}{ Spring } & \multicolumn{2}{|c|}{$0.17 \pm 0.08$} & \multicolumn{2}{|c|}{$0.55 \pm 0.13$} & \multicolumn{2}{|c|}{$0.13 \pm 0.07$} & $\mathrm{D}$ & 9.50 & $<0.05$ \\
\hline \multicolumn{2}{|l|}{ Summer } & \multicolumn{2}{|c|}{$1.09 \pm 0.19$} & \multicolumn{2}{|c|}{$0.82 \pm 0.30$} & \multicolumn{2}{|c|}{$0.75 \pm 0.10$} & $\mathrm{Ca} / \mathrm{Cr}$ & 4.53 & 0.10 \\
\hline \multicolumn{2}{|l|}{ Autumn } & \multicolumn{2}{|c|}{$0.31 \pm 0.06$} & \multicolumn{2}{|c|}{$0.26 \pm 0.08$} & \multicolumn{2}{|c|}{$1.28 \pm 0.35$} & $\mathrm{~N}$ & 8.40 & $<0.05$ \\
\hline$\chi^{2}$ value & $\mathrm{p}$ & 9.72 & $<0.05$ & 12.60 & $<0.05$ & 10.68 & $<0.05$ & & & \\
\hline \multicolumn{11}{|c|}{ Wild boar } \\
\hline \multicolumn{2}{|l|}{ Winter } & \multicolumn{2}{|c|}{$0.32 \pm 0.22$} & \multicolumn{2}{|c|}{$0.28 \pm 0.17$} & \multicolumn{2}{|c|}{$0.82 \pm 0.34$} & $\mathrm{Ca} / \mathrm{N}$ & 3.90 & 0.14 \\
\hline \multicolumn{2}{|l|}{ Spring } & \multicolumn{2}{|c|}{$0.47 \pm 0.36$} & \multicolumn{2}{|c|}{$0.63 \pm 0.48$} & \multicolumn{2}{|c|}{$0.52 \pm 0.29$} & $\mathrm{Ca}$ & 0.93 & 0.63 \\
\hline \multicolumn{2}{|l|}{ Summer } & \multicolumn{2}{|c|}{$0.06 \pm 0.03$} & \multicolumn{2}{|c|}{$0.30 \pm 0.07$} & \multicolumn{2}{|c|}{$0.10 \pm 0.03$} & $\mathrm{D}$ & 7.44 & $<0.05$ \\
\hline Autumn & & 0.1 & 0.07 & 0.31 & 0.11 & 0.57 & \pm 0.11 & $\mathrm{Ca} / \mathrm{N}$ & 4.53 & 0.10 \\
\hline$\chi^{2}$ value & $\mathrm{p}$ & 3.00 & 0.39 & 1.04 & 0.79 & 4.47 & 0.22 & & & \\
\hline
\end{tabular}

Note: values indicate average RAI and its error of mean. Differences in RAI among three time periods and seasons were tested by one-way ANOVA, main activity were categorised by Manly selection ratio. D, N, Cr and Ca indicate diurnal, nocturnal, crepuscular and cathemeral activity, respectively.

Table 5. Seasonal variations in daily activity patterns of large carnivores (wolf, lynx, bear) in the CFNR in 2013-2017

\begin{tabular}{|c|c|c|c|c|c|c|c|c|c|c|}
\hline \multirow{2}{*}{\multicolumn{2}{|c|}{ Season }} & \multirow{2}{*}{\multicolumn{2}{|c|}{$\begin{array}{c}\text { Twilight } \\
\mathrm{M} \pm \mathrm{m}\end{array}$}} & \multirow{2}{*}{\multicolumn{2}{|c|}{$\begin{array}{c}\text { Daytime } \\
\mathrm{M} \pm \mathrm{m}\end{array}$}} & \multirow{2}{*}{\multicolumn{2}{|c|}{$\begin{array}{c}\text { Nighttime } \\
\mathrm{M} \pm \mathrm{m}\end{array}$}} & \multirow{2}{*}{ Category } & \multirow{2}{*}{$\chi^{2}$ value } & \multirow[b]{2}{*}{$\mathrm{p}$} \\
\hline & & & & & & & & & & \\
\hline \multicolumn{11}{|c|}{ Grey wolf } \\
\hline \multicolumn{2}{|l|}{ Winter } & \multicolumn{2}{|c|}{$0.06 \pm 0.04$} & \multicolumn{2}{|c|}{$0.13 \pm 0.06$} & \multicolumn{2}{|c|}{$1.00 \pm 0.22$} & $\mathrm{~N}$ & 8.44 & $<0.05$ \\
\hline \multicolumn{2}{|l|}{ Spring } & \multicolumn{2}{|c|}{$0.28 \pm 0.09$} & \multicolumn{2}{|c|}{$0.70 \pm 0.15$} & \multicolumn{2}{|c|}{$0.64 \pm 0.16$} & $\mathrm{Ca}$ & 2.80 & 0.25 \\
\hline \multicolumn{2}{|l|}{ Summer } & \multicolumn{2}{|c|}{$0.36 \pm 0.04$} & \multicolumn{2}{|c|}{$0.73 \pm 0.09$} & \multicolumn{2}{|c|}{$0.38 \pm 0.12$} & $\mathrm{D}$ & 6.40 & $<0.05$ \\
\hline \multicolumn{2}{|l|}{ Autumn } & \multicolumn{2}{|c|}{$0.19 \pm 0.09$} & \multicolumn{2}{|c|}{$0.45 \pm 0.16$} & \multicolumn{2}{|c|}{$1.10 \pm 0.17$} & $\mathrm{~N}$ & 9.33 & $<0.05$ \\
\hline$\chi^{2}$ value & $\mathrm{p}$ & 9.52 & $<0.05$ & 6.84 & 0.08 & 7.80 & 0.05 & & & \\
\hline \multicolumn{11}{|c|}{ Eurasian lynx } \\
\hline \multicolumn{2}{|l|}{ Winter } & \multicolumn{2}{|c|}{$0.08 \pm 0.03$} & \multicolumn{2}{|c|}{$0.08 \pm 0.03$} & \multicolumn{2}{|c|}{$0.49 \pm 0.14$} & $\mathrm{~N}$ & 6.86 & $<0.05$ \\
\hline \multicolumn{2}{|l|}{ Spring } & \multicolumn{2}{|c|}{$0.31 \pm 0.14$} & \multicolumn{2}{|c|}{$0.49 \pm 0.12$} & \multicolumn{2}{|c|}{$0.62 \pm 0.09$} & $\mathrm{~N} / \mathrm{Ca}$ & 9.33 & $<0.05$ \\
\hline \multicolumn{2}{|l|}{ Summer } & 0.39 & 0.18 & 0.78 & 0.37 & 0.19 & 0.06 & $\mathrm{Ca} / \mathrm{D}$ & 4.78 & 0.09 \\
\hline Autumn & & 0.25 & 0.10 & 0.23 & 0.11 & 0.42 & 0.17 & $\mathrm{Ca}$ & 2.21 & 0.33 \\
\hline$\chi^{2}$ value & $\mathrm{p}$ & 3.06 & 0.38 & 9.24 & $<0.05$ & 8.51 & $<0.05$ & & & \\
\hline & & & & & Brov & bear & & & & \\
\hline Winter & & 0.03 & 0.02 & 0.03 & 0.02 & 0.02 & 0.02 & - & 2 & 0.37 \\
\hline Spring & & 0.13 & 0.07 & 0.96 & 0.18 & 0.21 & 0.07 & $\mathrm{D}$ & 9.29 & $<0.05$ \\
\hline Summer & & 0.53 & 0.11 & 1.70 & 0.39 & 0.44 & 0.11 & $\mathrm{D}$ & 7 & $<0.05$ \\
\hline Autumn & & 1.31 & 0.31 & 1.05 & 0.24 & 2.77 & 0.39 & $\mathrm{~N} / \mathrm{Cr}$ & 8.32 & $<0.05$ \\
\hline$\chi^{2}$ value & $\mathrm{p}$ & 14.13 & $<0.05$ & 12.12 & $<0.05$ & 12.67 & $<0.05$ & & & \\
\hline
\end{tabular}

Note: values indicate average RAI and its error of mean. Differences in RAI among three time periods and seasons were tested by one-way ANOVA, main activity were categorised by Manly selection ratio. D, N, Cr and Ca indicate diurnal, nocturnal, crepuscular and cathemeral activity, respectively.

Another situation was in the group of large carnivores (Table 5). The wolf had different activity times during the seasons $(\mathrm{W}=55.45, \mathrm{p}<0.05)$. It was nocturnal in autumn and winter. In spring, its activity was cathemeral, and in summer it became diurnal. The value of twilight, as well as daytime, was high only in spring and summer (Fig. 4). The lynx had a nocturnal life only in winter, the rest of the time it was cathemeral (spring, autumn), or had a trend for diurnal activity (summer). The lynx had the same time of activity during the year $(\mathrm{W}=5.19, \mathrm{p}=0.52)$. The bear had a bimodal type of activity during the entire waking period, but this was much stronger in summer and autumn than in spring. It retained a pronounced diurnal activity in spring and summer, and then sharply changed it in autumn to nocturnal and crepuscular. A significant change was indicated by high and reliable values (W $=47.91, \mathrm{p}<0.05)$. This feature, associated with the restructuring of the lifestyle during the hyperphagia period, distinguished the bear from all other species. Winter activity was rare, sporadic and was not characteristic of a species that falls into hibernation. 


\section{Activity overlaps of the different species}

Temporary niches of most species, one way or another, overlapped with each other (Fig. 5). If the activity of some animals was practically not conjugated, then others, on the contrary, strongly influenced each other (Table 6). Among the predatorprey pairs, the wolf and elk most clearly expressed a high degree of daily activity overlap $\left(\widehat{\Delta}_{4}=0.89\right)$. Other predator-prey pair as lynx and hare had a lower degree of overlap $\left(\widehat{\Delta}_{4}=0.75\right)$. Their coefficient of overlapping did not exceed that of elk or of wild boar - species with which the lynx, as a rule, does not contact. In the large carnivores group the bear and the wolf had a high degree of overlap with the lynx $\left(\widehat{\Delta}_{4}=0.88\right.$ and $\widehat{\Delta}_{4}=0.87$ respectively), whereas for the wolf and bear it was lower $\left(\widehat{\Delta}_{4}=\right.$ $0.80)$. Daily activities of ungulates were also very similar $\left(\widehat{\Delta}_{4}=0.81\right)$. The bear is the second predator that hunts on ungulates in CFNR, and its daily activity was not associated with them as much as for the wolf $\left(\widehat{\Delta}_{4}=0.78\right.$ with elk, $\widehat{\Delta}_{4}=0.82$ with wild boar $)$.

Grouping of species by similarity in activity patterns

From plots it becomes evident that completely different species can have common features of daily activity dynamics. With the help of factor analysis we can see how species group with each other by similarity in activity patterns. By the results of the values of the criteria of Kettel and Kaiser, the selection of three factors proved to be the most optimal ( $88.5 \%$ of explained variance). Two factor rotations showed the best data interpretation (Table 7). From the presented table it is clear that the first two factors group most of the variables in both cases. By the third factor, high correlation coefficients are observed only for one species.

Table 6. Coefficients of daily activity overlapping (Dhat4) and their CI for eight mammal species in the CFNR in 2010-2017

\begin{tabular}{|c|c|c|c|c|c|c|c|c|}
\hline Species & & & & & & & & \\
\hline Mountain hare & Mountain hare & & & & & & & \\
\hline Raccoon dog & $\begin{array}{c}0.79 \\
(0.74-0.83)\end{array}$ & Raccoon dog & & & & & & \\
\hline European badger & $\begin{array}{c}0.76 \\
(0.68-0.83)\end{array}$ & $\begin{array}{c}0.80 \\
(0.73-0.86)\end{array}$ & European badger & & & & & \\
\hline Elk & $\begin{array}{c}0.87 \\
(0.82-0.91)\end{array}$ & $\begin{array}{c}0.78 \\
(0.72-0.83)\end{array}$ & $\begin{array}{c}0.66 \\
(0.58-0.74)\end{array}$ & Elk & & & & \\
\hline Wild boar & $\begin{array}{c}0.70 \\
(0.64-0.76)\end{array}$ & $\begin{array}{c}0.74 \\
(0.67-0.80)\end{array}$ & $\begin{array}{c}0.54 \\
(0.47-0.62)\end{array}$ & $\begin{array}{c}0.81 \\
(0.75-0.87)\end{array}$ & Wild boar & & & \\
\hline Grey wolf & $\begin{array}{c}0.84 \\
(0.79-0.88)\end{array}$ & \begin{tabular}{|c|}
0.75 \\
$(0.70-0.81)$ \\
\end{tabular} & $\begin{array}{c}0.63 \\
(0.55-0.71)\end{array}$ & $\begin{array}{c}0.89 \\
(0.84-0.93)\end{array}$ & $\begin{array}{c}0.78 \\
(0.71-0.84)\end{array}$ & Grey wolf & & \\
\hline Eurasian lynx & $\begin{array}{c}0.75 \\
(0.70-0.81)\end{array}$ & $\begin{array}{c}0.65 \\
(0.59-0.71) \\
\end{array}$ & $\begin{array}{c}0.52 \\
(0.44-0.61)\end{array}$ & $\begin{array}{c}0.83 \\
(0.78-0.89)\end{array}$ & $\begin{array}{c}0.82 \\
(0.76-0.88)\end{array}$ & $\begin{array}{c}0.87 \\
(0.82-0.92)\end{array}$ & Eurasian lynx & \\
\hline Brown bear & $\begin{array}{c}0.67 \\
(0.63-0.72)\end{array}$ & $\begin{array}{c}0.62 \\
(0.56-0.67)\end{array}$ & $\begin{array}{c}0.45 \\
(0.37-0.52)\end{array}$ & $\begin{array}{c}0.78 \\
(0.73-0.82)\end{array}$ & $\begin{array}{c}0.82 \\
(0.76-0.86)\end{array}$ & $\begin{array}{c}0.80 \\
(0.76-0.85)\end{array}$ & $\begin{array}{c}0.88 \\
(0.84-0.92)\end{array}$ & Brown bear \\
\hline
\end{tabular}

Table 7. Factor loadings for variables in the space of three factors for eight mammal species in the CFNR for the period 2010-2017. Present two methods of factor rotation: varimax raw and quartimax normalised

\begin{tabular}{|l|c|c|c|c|c|c|}
\hline \multirow{2}{*}{ Species } & \multicolumn{3}{|c|}{ Varimax raw, loadings } & \multicolumn{3}{c|}{ Quartimax normalised, loadings } \\
\cline { 2 - 7 } & Factor 1 & Factor 2 & Factor 3 & Factor 1 & Factor 2 & Factor 3 \\
\hline Mountain hare & $\mathbf{0 . 7 9 9 3}$ & 0.4831 & 0.1298 & $\mathbf{0 . 9 0 0 1}$ & 0.2740 & 0.0623 \\
\hline Raccoon dog & $\mathbf{0 . 9 6 0 6}$ & -0.1183 & 0.1377 & $\mathbf{0 . 8 9 6 0}$ & -0.3316 & 0.2075 \\
\hline European badger & $\mathbf{0 . 9 7 3 2}$ & 0.0436 & -0.0003 & $\mathbf{0 . 9 4 9 7}$ & -0.2132 & 0.0387 \\
\hline Elk & 0.5924 & 0.6794 & 0.1692 & $\mathbf{0 . 7 5 3 2}$ & 0.5212 & 0.0481 \\
\hline Wild boar & 0.2026 & 0.1138 & $\mathbf{0 . 9 5 1 7}$ & 0.2345 & 0.2642 & $\mathbf{0 . 9 1 3 8}$ \\
\hline Grey wolf & 0.5434 & $\mathbf{0 . 7 2 0 9}$ & -0.0773 & $\mathbf{0 . 7 1 4 6}$ & 0.5185 & -0.2036 \\
\hline Eurasian lynx & -0.0846 & $\mathbf{0 . 8 6 7 8}$ & 0.1848 & 0.1507 & $\mathbf{0 . 8 7 8 4}$ & -0.0108 \\
\hline Brown bear & -0.2611 & 0.6860 & 0.5761 & -0.0640 & $\mathbf{0 . 8 4 0 0}$ & 0.4012 \\
\hline Explained variance & 3.2713 & 2.4673 & 1.3422 & 3.6747 & 2.3179 & 1.0882 \\
\hline Total proportion, \% & 40.89 & 30.84 & 16.78 & 45.93 & 28.97 & 13.60 \\
\hline
\end{tabular}

Note: factor loadings greater than 0.70 are highlighted in bold type. 

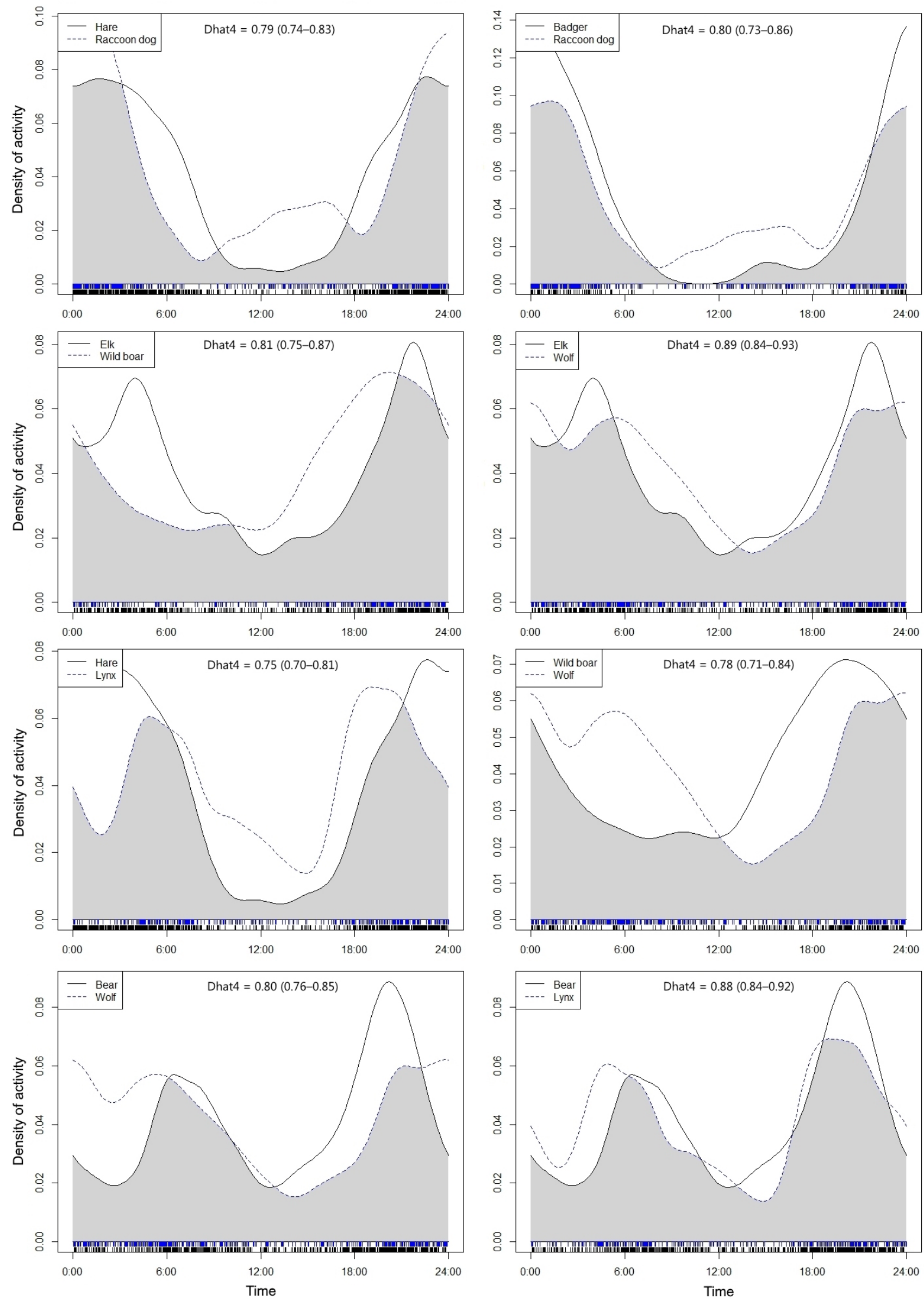

Fig. 5. Daily activity overlaps and their estimators (Dhat4 and CI) between eight mammal species in the CFNR in 2010-2017. Solid and dashed lines, bars and grey shaded area indicate kernel densities of two species, trap events and overlap coefficient respectively. 
In both methods factor 1 can be interpreted as a mostly nocturnal activity with a propensity for a unimodal or weakly-expressed bimodal type. The maximum positive values of factor 1 correspond to the night hours (from 10 p.m. to 3 a.m.) with a peak at midnight (factor scores 1.72-1.99). Factor 2 reflects the cathemeral activity of a bimodal type with maximum positive values from 4 a.m. to 7 a.m. and 6 p.m. to 9 p.m. Factor 3 shows a greater degree of relation to the second half of the daytime and evening activity pattern with maximum values for 4-10 p.m. and peak at 7 p.m. (factor scores 2.39-2.61).

The graphical representation of loadings in the coordinates of the three factors is shown in Fig. 6. The eight studied species can be divided into three sufficiently isolated groups according to their location relative to the axes of factors, which reflects the features of their daily activity patterns. The first group is the most numerous and includes species with a tendency to mostly nocturnal activity. These are the wolf, elk, hare, badger, and raccoon dog. In the second group are animals with bimodal activity of the cathemeral type, which include the bear and lynx. In the third group is found only the wild boar, the activity of which is confined to the evening hours.

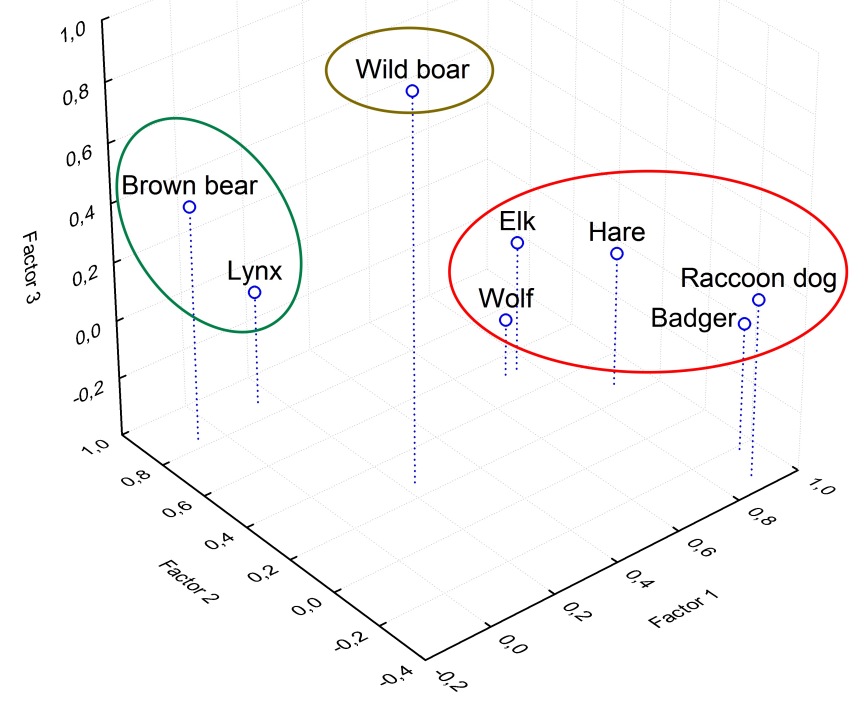

Fig. 6. The space of axes of the three factors for the factor loadings of eight mammal species in the CFNR in 2010 2017. Factor analysis by the principal component method, quartimax normalised rotation. Ovals are identified species close to each other in the space of factor axes.
The varimax raw method showed that in the first group, the maximum factor loadings corresponded to the badger (factor 1, 0.97) and the raccoon dog (0.96), which preferred night-time (Table 7). The hare had a smaller value for this factor (only 0.80 ). The badger had also high crepuscular activity especially in the morning. It was followed by the raccoon dog, whose activity was also mostly nocturnal, but with a higher coverage of the daylight time. At the same time, a weak negative ratio of the raccoon dog to morning and evening activity (factor 2, -0.12) was observed, which was more pronounced than for the hare (factor 2, 0.48). Due to this difference, as well as the greater activity of the raccoon dog in daytime, the spatial position of these species in the coordinate space was rather scattered (Fig. 6).

The second group represented cathemeral species with more diurnal activity, especially true for the lynx, which also had more pronounced crepuscular activity (factor 2, 0.87). The bear had a smoother crepuscular activity than the lynx (0.69), but with a big peak at the end of daytime. This made its connection with factor 3 stronger $(0.58)$, while for the lynx this connection was weak (0.19). The pair wolf-elk showed a close relationship not only in coefficient of overlap, but both in terms of factor loadings (Table 7). These species take interstitial position between two factors and are attracted to the bear-lynx group (Fig. 6).

An even greater than the bear's activity in the second half of the daytime was observed for the wild boar. According to his special relation to factor 3 , he was singled out in a special group. The rhythm of its activity was somewhat ragged, revealing most of the records in the afternoon, evening and early night (0.95). Also it had the lowest morning and late night activity.

Since 2017 there seemed to be a tendency that the wolf-elk pair has been moving away from other nocturnal animals and formed their own 4-th factor. From this year they left the group of strictlynocturnal animals and passed to crepuscular group, but they still have a link with a nighttime period (Table 7). The bear seemed to have a tendency being more similar to the wild boar than to the lynx because of an increasing evening activity (factor $3,0.58$ ) and the lynx in contrary - raised activity in the morning. The quartimax normalised method maximises the variance of factor loadings squares and normalised them. In this case both the wolf and elk were still in the first group of nocturnal animals and the bear had a higher score value for crepuscular time than for only «evening» (Table 7). 


\section{Discussion}

The movement activity of animals depends on a number of factors. Daily activity is determined both by external factors of the environment, and endogenous factors of the animals themselves, their physiological state. Among the external factors besides the abiotic factors (light, temperature, weather severity, precipitation, etc.), biotic influences are of great importance. For many carnivores, these are the rhythms of activity of the main victims, for ungulates and hares - optimal protective conditions from enemies to meet energy needs. By the example of the European lynx it was convincingly shown that within the latitudinal gradient of Europe the duration of the light part of the day was not the leading factor determining its activity rhythms. They are the endogenous processes and peculiarities of the behaviour of the main hunting objects that determined the dynamics of the movements of this predator (Heurich et al., 2014). The daily rhythm of mammals is sometimes subject of a significant variability both during the year and within different age and gender groups, as is confirmed by several species studied (Homolka, 1986; Pépin \& Cargnelutti, 1994; Kaczensky et al., 2006; Kolbe \& Squires, 2007).

Most of the mammals we have examined show activity at night and twilight. At the same time, the most active among all was the hare, which dominated the night and twilight registrations. This is a numerous species for the territory of the reserve, the movement of which is not directly related to the network of glades and roads, along which the camera traps were arranged. The hare is a nocturnal animal with an important part of twilight activity. In daytime, especially around midday, the hare was moving quite a bit, apparently using this time for rest. This type of activity is determined by a combination of conditions that ensure generally a relatively safe existence of the species (safety of obtaining feed, survival of young animals and so on). With the help of the method of radio telemetry, it was established earlier that the hare is predominantly nocturnal. According to Pépin \& Cargnelutti (1994), the activity of Lepus europaeus (L.) begins an average of 23 minutes after sunset and ends 14 minutes before sunrise. Nevertheless, these authors noted that among the individuals, the activity is different, especially in the afternoon and in the second half of the night. In summer, the hare's activity can shift to daytime, as a short night is not able to provide the necessary time for the energy needs of the animal (Schai-Braun et al., 2012).
In winter, hares are exclusively nocturnal animals. Males are active throughout the night, and females have a decline at midnight (Zaccaroni et al., 2013). In our case, the hare clearly preferred the morning activity in spring, which, seem to be due to the molting and birth of the young. In summer it had a high diurnal activity, and in winter it led a strictly nocturnal lifestyle. That is why in the CFNR the hare had a bit another activity pattern than that in Hokkaido (Japan), where it was clearly inactive during daytime (Ikeda et al., 2016).

In many respects the hare has a similar pattern of movements like the raccoon dog, whose activity can be defined as mostly nocturnal too. Unlike the hare, the raccoon dog had a weak peak during the daytime and was less active at night. In winter, it fell into winter sleep in burrows and shelters, but periodically woke up and made short transitions. The maximum activity as a whole was typical for the summer and early autumn periods, not only at night and twilight, but also during daytime. Part of this was due to the intensive growth and development of the territory by young animals, which were engaged in almost round-the-clock activity, beginning in August. In late autumn, the raccoon dog became less mobile and focused more on the fodder areas for the accumulation of fat. This is in agreement with the results of German and Japanese authors in which the raccoon dog was predominantly nocturnal but also had an increased diurnal activity during the period of puppies' upbringing, i.e. in summer (Zoller \& Drygala, 2013; Ikeda et al., 2016).

The badger closes the top three of the mostly nocturnal animals, presenting in this case a classic example of a unimodal nighttime activity. The activity of its movements was almost entirely confined to the twilight and night time. In the studies of many other authors, it was noted that European populations of the badger are characterised by a crepuscular-nocturnal activity (Goszczyński et al., 2005; Rosalino et al., 2005 etc.), while they are often recorded near the burrows and on the surface of settlements during daytime (Sidorchuk \& Rozhnov, 2010; Sidorchuk et al., 2014). After a daytime minimum of activity in the settlements there is a second one at night, which the authors associate with the search for forage away from their burrows. The data obtained by us confirm this assumption, since it is at this time that the maximum movement activity outside the settlements was observed.

The wild boar is not a typical species for the CFNR. Its distribution is confined mainly to the periphery of the reserve. While the registrations of 
other mammals studied were fairly evenly distributed over the locations, the wild boar was recorded mainly in three places remote from the central spruce arrays of the reserve. The activity of this animal was mainly associated with the transitions from its daytime and nighttime beds to the feeding places. The wild boar turned out to be the only species determined by the results of factor analysis in the third group, i.e. mainly evening animals. According to the frequency of registrations during the day, he was not like the others. It was characterised by rhythmic fluctuations of activity from midnight to noon, and then uniform growth to evening twilight. The peak of the evening registrations of the wild boar was also noted in studies using camera traps in Romania (Marcon et al., 2017).

In North America the moose (Alces alces gigas Miller, 1899) had mostly a crepuscular activity (Gillingham \& Klein, 1992). In our study the elk had the biggest activity in the twilight period compared to all other species $\left(w_{i}=1.71\right)$, which correspond with the American authors. In the daily registrations of the wolf and elk, there was a close relationship, which was shown in a high degree of overlap $\left(\widehat{\Delta}_{4}=0.89\right)$. A possible explanation for this lies in the adaptation of the predator to the daily rhythm of its prey. On the territory of the CFNR, the elk is the main victim of the wolf (Kochetkov, 1991). During periods of the greatest activity of these ungulates, predators are easier to get on their trail and begin chasing. In a recent study in the Eastern Carpathians (Romania), the activity rhythms of the wolf and the deer (Cervus elaphus Linnaeus, 1758) coincided worse $\left(\widehat{\Delta}_{1}=0.61\right)$, while the best was with the wild boar and brown bear $\left(\widehat{\Delta}_{1}=0.77\right)$ (Marcon et al., 2017). In our study the wolf had a less high overlapping with brown bear $\left(\widehat{\Delta}_{4}=0.80\right)$ and wild boar $\left(\widehat{\Delta}_{4}=0.78\right)$.

The lynx has a typical bimodal type of activity of the cathemeral form. It was found that in Europe, the lynx rhythm is more influenced not by the light regime, but by the activity of its main victims reindeer (Rangifer tarandus (Linnaeus, 1758)) and roe deer (Capreolus capreolus (Linnaeus, 1758)) (Heurich et al., 2014). However, despite the fact that the main predator food object on the territory of the reserve is the hare, there was no essential overlapping in their activities $\left(\widehat{\Delta}_{4}=0.75\right)$. Similarly, the lack of clear synchronism between the daily activity of the Canadian lynx (Lynx canadensis Kerr, 1792) and the American hare (Lepus americanus Erxleben, 1777) was noted in the USA in the state of Montana (Kolbe \& Squires, 2007). In general, the data obtained with the help of camera traps coincide with the information on the predator's visual meetings on the same territory (Zheltukhin, 1987). According to material from camera traps in British Columbia, Canada, $46 \%$ of the Canadian lynx registrations were in the daytime, $48 \%$ in the nighttime and $6 \%$ in the twilight period, and the peak activity was from 3 p.m. to 6 p.m. (Crowley et al., 2013). The radio telemetry method showed quite similar data for the Canadian lynx in Montana (Kolbe \& Squires, 2007). In Europe, the lynx leads a more crepuscular (Podolski et al., 2013) or a nocturnal lifestyle (Schmidt, 1999). For the Polish lynx, only one peak of night activity was noted, which had a slight decline between 8 p.m. and 10 p.m. (ibid.). It is interesting that at this time according to our data the peak of evening activity ends and the phase of night passivity begin. It was noted that a nocturnal activity of the lynx is more typical for places with a high level of anxiety for the human (Lendrum et al., 2017). In conditions of observance of the protected regime, it is most likely to expect a typical form of behaviour, i.e. a cathemeral activity, which brings our lynx closer to the Canadian one, rather than to a relative of the one in densely populated Europe.

The activity patterns of the brown bear were studied by us earlier in various ways: camera traps (Ogurtsov \& Zheltukhin, 2017), visual observations on oat fields, a survey of local residents about visual encounters. All of them give generally similar results. In addition, they are confirmed by data from other researchers who studied bears both by telemetry (Garshelis \& Pelton, 1980; Roth, 1983; Clevenger et al., 1990; Lariviere et al., 1994; Kaczensky et al., 2006; Munro et al., 2006; Seryodkin et al., 2013), camera traps (Bridges et al., 2004; Partridge et al., 2009; Ikeda et al., 2016) and other methods (Loskutov et al., 1993; Craighead et al., 1995). In the CFNR the bear is a cathemeral animal with a bimodal type of activity with a predominance of registrations in the second half of the daytime. This «evening» activity is not uniform during the seasons of the year, increasing from the end of summer to the middle of autumn - the peak of the hyperphagia period. At these moments it is similar to results obtained in Japan (Ikeda et al., 2016).

No avoidance between the studied species has been noticed. All three large carnivores of the CFNR occupy in many ways a similar temporary niche, but have different trophic niches. The wolf hunts mainly on elk, with which it has a high degree of overlap, as well as on the wild boar. The bear in 
the study area feeds on elk and wild boar too, but mainly in the spring period and mostly adheres to a vegetable diet in other time (Ogurtsov, 2018). The main victim of the lynx is the hare and hazel grouse (Bonasa bonasia (Linnaeus, 1758)) (Zheltukhin, 1987). Thus, there is no pronounced food competition among these species in the CFNR and large carnivores exhibit a high degree of activity overlap with each other. The activity of omnivorous medium-sized animals, such as the badger and raccoon dog, is shifted to the nighttime, but competition for food between them has not been noted either.

\section{Conclusions}

Previously, the technical capabilities of camera traps did not allow for a long-term twenty-four-hour observation, which was noted as the main drawback of this method (Ball, 1980; Partridge et al., 2009). The bulky additional power elements, the complexity of technical operation, the impossibility of highquality shooting at night - all this imposed significant limitations on the possibilities of using these devices (ibid.). Modern cameras almost completely eliminate this drawback. On the territory of the Central Forest Nature Reserve, camera traps operate permanently throughout the year and over a long period (from five to eight years). The quality of the Reconyx camera traps allows taking pictures of a good quality at any time of the day with a high rate of release of the camera trigger. All of this makes it possible to obtain a large amount of data for detail analysis of daily activity patterns of mammals.

Since the camera traps have a constant position, they are able to track the dynamics of animal movements only in the places of their locations, which makes it impossible to study the daily rhythms of all activity. When staging cameras along the mammalian pathways (glades, paths, forest roads), it is possible to collect information only about the activity of the movement of those species that constantly use these paths. Thus, a lot of information remains behind the scenes, and we can only guess how active the animal was at other times outside the camera eye in studied locations. All considered animals show different types of activity also outside the path of movement, for example, in their lairs, burrows, resting places or fodder areas. To study the most complete rhythm of activity, it is necessary to investigate all these aspects and to set up camera traps in appropriate places. The most complex, but also expensive, studies are possible with a combination of different methods, such as camera traps, GPS and radio telemetry, as was recently done to study brown bears in the eastern Alps (Seganfreddo et al., 2017) or in combination with traps for collecting hair (Partridge et al., 2009). In our case, we can interpolate the activity of movements over large time limits due to the fairly wide coverage of the territory by camera traps and the longtime of their work.

\section{Acknowledgments}

The authors are grateful to the chief scientist of the Laboratory of Biogeocoenology of the A.N. Severtsov Institute of Ecology and Evolution of RAS (Moscow, Russia) Prof. Yu.G. Puzachenko for consultations in working with camera traps. We also thank Takashi Ikeda (Faculty of Environmental Earth Science, Hokkaido University, Sapporo, Hokkaido, Japan) for helpful advices and anonymous reviewers for valuable comments and remarks for improving this article. The work was supported by the RFBR (13-04-00221-a).

\section{References}

Alexy K.J., Brunjes K.J., Gassett J.W., Miller K.V. 2003. Continuous remote monitoring of gopher tortoise burrow use. Wildlife Society Bulletin 31: 1240-1243.

Ball E.R. 1980. Time-lapse cameras as an aid in studying grizzly bears in northwest Wyoming. In: Fourth International Conference on Bear Research and Management (February 1977, Kalispell, MT, USA). Vol. 4. Morges, Switzerland: International Association for Bear Research and Management. P. 331-335. DOI: 10.2307/3872888

Bridges A.S., Vaughan M.R., Klenzendorf S. 2004. Seasonal variation in American black bear Ursus americanus activity patterns: quantification via remote photography. Wildlife Biology 10: 277-284.

Bridges A.S., Noss A.J. 2011. Behavior and activity patterns. In: A.F. O'Connell, J.D. Nichols, U.K. Karanth (Eds.): Camera traps in animal ecology: methods and analyses. $1^{\text {st }}$ edition. New York: Springer. P. 57-69. DOI: 10.1007/978-4-431-99495-4

Brown J., Gehrt S.D. 2009. The basics of using remote cameras to monitor wildlife. Fact sheet. Agriculture and natural resources. Columbus: Ohio State University Extension. 8 p.

Bu H., Wang F., McShea W.J., Lu Z., Wang D., Li S. 2016. Spatial co-occurrence and activity patterns of mesocarnivores in the temperate forests of southwest China. PLOS ONE 11(10): e0164271. DOI: 10.1371/journal.pone.0164271

Carthew S.M., Slater E. 1991. Monitoring animal activity with automated photography. Journal of Wildlife Management 55(4): 689-692. DOI: 10.2307/3809519

Chen M-T., Tewes M.E., Pei K.J., Grassman Jr. L.I. 2009. Activity patterns and habitat use of sympatric small carnivores in southern of Taiwan. Mammalia 73(1): 20-26. DOI: 10.1515/MAMM.2009.006

Claridge A.W., Mifsud G., Dawson J., Saxon M.J. 2004. Use of infrared digital cameras to investigate the behavior of cryptic species. Wildlife Research 31(6): 645-650. DOI: 10.1071/WR03072 
Clevenger A.P., Purroy F.J., Pelton M.R. 1990. Movement and activity patterns of a European brown bear in the Cantabrian Mountains, Spain. In: Eighth International Conference on Bear Research and Management (Victoria, British Columbia, Canada, February 1989). Vol. 8. International Association of Bear Research and Management. P. 205-211. DOI: 10.2307/3872920

Craighead J.J., Sumner J.S., Mitchell J.A. 1995. The grizzly bears of Yellowstone. Their ecology in the Yellowstone Ecosystem, 1959-1992. Washington, D.C.: Island Press. 556 p.

Crowley S.M., Hodder D.P., Larse K.W. 2013. Canada lynx (Lynx canadensis) detection and behavior using remote cameras during the breeding season. Canadian Field-Naturalist 127(4): 310-318. DOI: 10.22621/cfn.v127i4.1512

Di Bitetti M.S., Paviolo A., De Angelo C. 2006. Density, habitat use and activity patterns of ocelots (Leopardus pardalis) in the Atlantic Forest of Misiones, Argentina. Journal of Zoology 270(1): 153-163. DOI: 10.1111/j.1469-7998.2006.00102.x

Foster V.C., Sarmento P., Sollmann R., Tôrres N., Jácomo A.T.A., Negrões N., Fonseca C., Silveira L. 2013. Jaguar and puma activity patterns and predator-prey interactions in four Brazilian biomes. Biotropica 45(3): 373-379. DOI: 10.1111/btp.12021

Garshelis D.L., Pelton M.R. 1980. Activity of black bears in the Great Smoky Mountains National Park. Journal of Mammalogy 61(1): 8-19. DOI: 10.2307/1379952

Gerber B.D., Karpanty S.M., Randrianantenaina J. 2012. Activity patterns of carnivores in the rain forests of Madagascar: implications for species coexistence. Journal of Mammalogy 93(3): 667-676. DOI: 10.1644/11-mamm-a-265.1

Gillingham M.P., Klein D.R. 1992. Late-winter activity patterns of moose (Alces alces gigas) in western Alaska. Canadian Journal of Zoology 70(2): 293-299. DOI: 10.1139/z92-044

Gómez H., Wallace R.B., Ayala G., Tejada R. 2005. Dry season activity patterns for some Amazonian mammals. Studies of Neotropical Fauna and the Environment 40(2): 91-95. DOI: 10.1080/01650520500129638

Goszczyński J., Juszko S., Pacia A., Skoczyńska J. 2005. Activity of badgers (Meles meles) in Central Poland. Mammalian Biology 70(1): 1-11. DOI: 10.1078/16165047-00171

Heurich M., Hilger A., Küchenhoff H., Andrén H., Bufka L., Krofel M., Mattisson J., Odden J., Persson J., Rauset G.R., Schmidt K., Linnell J.D.C. 2014. Activity patterns of Eurasian lynx are modulated by light regime and individual traits over a wide latitudinal range. PLoS ONE 9(12): e114143. DOI: 10.1371/journal.pone.0114143

Hernández-SaintMartín A.D., Rosas-Rosas O.C., PalacioNúñez J., Tarango-Arámbula L.A., Clemente-Sánchez F., Hoogesteijn A.L. 2013. Activity patterns of jaguar, puma and their potential prey in San Luis Potosí, Mexico. Acta Zoológica Mexicana 29(3): 520-533.
Homolka M. 1986. Daily activity pattern of the European hare (Lepus europaeus). Folia Zoologica 35(1): 33-42.

Ikeda T., Uchida K., Matsuura Y., Takahashi H., Yoshida T., Kaji K., Koizumi I. 2016. Seasonal and diel activity patterns of eight sympatric mammals in Northern Japan revealed by an intensive camera-trap survey. PLoS ONE 11(10): e0163602. DOI: 10.1371/journal. pone.0163602

Kaczensky P., Huber D., Knauer F., Roth H., Wagner A., Kusak J. 2006. Activity patterns of brown bears (Ursus arctos) in Slovenia and Croatia. Journal of Zoology 269(4): 474-485. DOI: 10.1111/j.1469-7998.2006.00114.x

Kelly M.J., Holub E.L. 2008. Camera trapping of carnivores: trap success among camera types and across species and habitat selection by species on Salt Pond Mountain Giles County, Virginia. Northeastern naturalist 15(2): 249-262. DOI: 10.1656/1092-6194(2008)15[249:CT OCTS]2.0.CO;2

Kochetkov V.V. 1991. Wolf and moose: trend of behavior of predator and prey. In: 22-nd International Ethological Conference. Kyoto, Japan.

Kolbe J.A., Squires J.R. 2007. Circadian activity patterns of Canada lynx in western Montana. Journal of Wildlife Management 71(5): 1607-1611. DOI: 10.2193/2005-727

Koprowski J.L., Corse M.C. 2005. Time budgets, activity periods, and behavior of Mexican fox squirrels. Journal of Mammalogy 86(5): 947-952. DOI: 10.1644/1545-1542(2005)86[947:TBAPAB]2.0.CO;2

Lariviere S., Huot J., Samson C. 1994. Daily activity patterns of female black bears in a northern mixed-forest environment. Journal of Mammalogy 75(3): 613-620. DOI: $10.2307 / 1382508$

Lendrum P., Crooks R.K., Wittemyer G. 2017. Changes in circadian activity patterns of a wildlife community post high-intensity energy development. Journal of Mammalogy 98(5): 1265-1271. DOI: 10.1093/jmammal/gyx097

Linkie M., Ridout M.S. 2011. Assessing tiger-prey interactions in Sumatran rainforests. Journal of Zoology 284(3): 224-229. DOI: 10.1111/j.1469-7998.2011.00801.x

López González C.A., Lorenzana Piña G. 2002. Carrion use by jaguars (Panthera onca) in Sonora, Mexico. Mammalia 66(4): 603-605.

Loskutov A.V., Pavlov M.P., Puchkovskiy S.V. 1993. The Volga-Kama region. In: M.A. Vaisfeld, I.E. Chestin (Eds.): Bears: brown bear, polar bear, Asian black bear. Distribution, ecology, use and protection. Moscow: Nauka. P. 132-135.

Lucherini M., Reppucci J.I., Walker R.S., Villalba M.L., Wurstten A., Gallardo G., Iriarte A., Villalobos R., Perovic P. 2009. Activity pattern segregation of carnivores in the High Andes. Journal of Mammalogy 90(6): 1404-1409. DOI: 10.1644/09-MAMM-A-002R.1

Lund U., Agostinelli C., Arai H., Gagliardi A., Portugues E.G., Giunchi D., Irisson J.O., Pocernich M., Rotolo F. 2017. Circular statistics. R package version 0.4-93. Available from: https://cran.r-project.org/package $=$ circular 
MacArthur R.H., Pianka E.R. 1966. On optimal use of a patchy environment. American Naturalist 100: 603609. DOI: $10.1086 / 282454$

Maffei L., Paredes R., Segundo A., Noss A.J. 2007. Home range and activity of two sympatric fox species in the Bolivian dry Chaco. Canid News 10.4. Available from: http://www.canids.org/canidnews/10/Sympatric foxes in Bolivia.pdf

Manly B.F.J., McDonald L.L., Thomas D.L., McDonald T.L., Erickson W.P. 2002. Resource selection by animals: statistical design and analysis for field studies. $2^{\text {nd }}$ edition. Netherlands: Springer. 221 p. DOI: 10.1007/978-94-011-1558-2

Marcon A., Chiriac S., Corradini A., Pop I.-M., Oliveira T., Sin T., Gazzola A. 2017. Diel activity overlap of wolf and sympatric large mammals as revealed by a cameratrapping survey in the Eastern Carpathians, Romania. In: $10^{\text {th }}$ Baltic Theriological conference (27-30 September 2017). Tartu. Estonia. P. 54.

Matiukhina D.S., Vitkalova A.V., Rybin A.N., Aramilev V.V., Shevtsova E.I., Miquelle D.G. 2016. Camera-trap monitoring of Amur Tiger (Panthera tigris altaica) in southwest Primorsky Krai, 2013-2016: preliminary results. Nature Conservation Research 1(3): 36-43. DOI: 10.24189/ncr.2016.025

Meek P.D., Ballard G., Fleming P. 2012. An introduction to camera trapping for wildlife surveys in Australia. Canbera, Australia: Invasive Animals Cooperative Research Centre. Forest Road, Orange: NSW Department of Primary Industries. $85 \mathrm{p}$.

Meek P.D., Ballard G., Claridge A., Kays R., Moseby K., O’Brien T., O’Connell A., Sanderson J., Swann D., Tobler M., Townsend S. 2014. Recommended guiding principles for reporting on camera trapping research. Biodiversity and Conservation 23(9): 2321-2343. DOI: 10.1007/s10531-014-0712-8

Meredith M., Ridout M.S. 2017. Estimates of coefficient of overlapping for animal activity patterns. R package version 0.3.0. Available from: https://cran.r-project.org/package=overlap

Mohamad S.W., Darmaraj M.R. 2009. A general guide to camera-trapping large mammals in tropical rainforests with particular reference to tigers. WWF-Malaysia. $37 \mathrm{p}$.

Mohd-Azlan J., Sharma D.S.K. 2006. The diversity and activity patterns of wild felids in a secondary forest in Peninsular Malaysia. Oryx 40(1): 36-41. DOI: 10.1017/ S0030605306000147

Munro R.H.M., Nielsen S.E., Price M.H., Stenhouse G.B., Boyce M.S. 2006. Seasonal and diel patterns of grizzly bear diet and activity in West-Central Alberta. Journal of Mammalogy 87(6): 1112-1121. DOI: 10.1644/05-MAMM-A-410R3.1

Niedballa J., Courtiol A., Sollmann R., Mathai J., Wong S.T., Nguyen A.T.T., Mohamed A., Tilker A., Wilting A. 2016. Camera trap data management and preparation of occupancy and spatial capture-recapture analyses. $R$ package version 0.99.9. Available from: https://cran.rproject.org/package $=$ camtrapR
Ogurtsov S.S., Zheltukhin A.S. 2017. Application of camera traps to the study of a brown bear (Ursus arctos) population in the Central Forest Nature Reserve. Zoologicheskii zhurnal 96(3): 360-372. DOI: 10.7868/ S0044513417030084 [In Russian]

Ogurtsov S.S. 2018. The diet of the brown bear (Ursus arctos) in the Central Forest Nature Reserve (Russia), based on scat analysis data. Zoologicheskii zhurnal 97(4): 486502. DOI: 10.7868/S0044513418040104 [In Russian]

Olchev A., Novenko E., Popov V., Pampura T., Meili M. 2017. Evidence of temperature and precipitation change over the past 100 years in a high-resolution pollen record from the boreal forest of Central European Russia. The Holocene 27(5): 740-751. DOI: 10.1177/0959683616670472

Partridge S., Smith T., Lewis T. 2009. Black and brown bear activity at selected coastal sites in Glacier Bay national park and preserve. Alaska: a preliminary assessment using noninvasive procedures. Open file report. Reston, Virginia: U.S. Geological Survey. 73 p.

Pépin D., Cargnelutti B. 1994. Individual variations of daily activity patterns in radiotracked European hares during winter. Acta Theriologica 39(4): 399-409.

Podolski I., Belotti E., Bufka L., Reulen H., Heurich M. 2013. Seasonal and daily activity patterns of free-living Eurasian lynx Lynx lynx in relation to availability of kills. Wildlife Biology 19(1): 69-77. DOI: 10.2981/12-049

Porfirio G., Foster V.C., Fonseca C., Sarmento P. 2016. Activity patterns of ocelots and their potential prey in the Brazilian Pantanal. Mammalian Biology-Zeitschrift für Säugetierkunde 81(5): 511-517. DOI: 10.1016/j. mambio.2016.06.006

Puzachenko Yu.G., Zheltukhin A.S., Kozlov D.N., Korablyov N.P., Fedyaeva M.V., Puzachenko M.Ju., Siunova E.V. 2016. Central Forest State Nature Biosphere Reserve. Popular scientific booklet. $2^{\text {nd }}$ edition. Tver: «Pechatnya» publishing house. $80 \mathrm{p}$.

R Development Core Team. 2015. R: a language and environment for statistical computing. Vienna, Austria: $\mathrm{R}$ Foundation for Statistical Computing. Available from: http://www.R-project.org

Ridout M.S., Linkie M. 2009. Estimating overlap of daily activity patterns from camera trap data. Journal of Agricultural, Biological, and Environmental Statistics 14(3): 322-337. DOI: 10.1198/jabes.2009.08038

Romero-Muñoz A., Maffei L., Cuéllar E., Noss A.J. 2010. Temporal separation between jaguar and puma in the dry forests of southern Bolivia. Journal of Tropical Ecology 26(3): 303-311. DOI: 10.1017/S0266467410000052

Rosalino L.M., Macdonald D.W., Santos-Reis M. 2005. Activity rhythms, movements and patterns of sett use by badgers Meles meles in a Mediterranean woodland. Mammalia 69(3-4): 395-408. DOI: 10.1515/ mamm.2005.031

Ross J., Hearn A.J., Johnson P.J., Macdonald D.W. 2013. Activity patterns and temporal avoidance by prey in 
response to Sunda clouded leopard predation risk. Journal of Zoology 290(2): 96-106. DOI: 10.1111/jzo.12018

Roth H.U. 1983. Diel activity of a remnant population of European brown bears. In: Fifth International Conference on Bear Research and Management (Madison, Wisconsin, USA, February 1980). Vol. 5. International Association of Bear Research and Management. P. 223-229. DOI: $10.2307 / 3872541$

Roth H.U., Huber D. 1986. Diel activity of brown bears in Plitvice Lakes National Park. Yugoslavia. In: Sixth International Conference on Bear Research and Management (Grand Canyon, Arizona, USA, February 1983). Vol. 6. International Association of Bear Research and Management. P. 177-181. DOI: $10.2307 / 3872822$

Rovero F., Martin E., Rosa M., Ahumada J.A., Spitale D. 2014. Estimating species richness and modelling habitat preferences of tropical forest mammals from camera trap data. PLoS ONE 9(7): e103300. DOI: 10.1371/ journal.pone.0103300

Rozhnov V.V., Naidenko S.V., Hernandez-Blanco J.A., Lukarevskii V.S., Sorokin P.A., Maslov M.V., Litvinov M.N., Kotlyar A.K. 2012. Seasonal changes in the abundance of Amur tiger preys: an experience of applying a matrix of photocameras. Zoologicheskii zhurnal 91(6): 746-756. [In Russian]

Schai-Braun S., Rödel H.G., Hackländer K. 2012. The influence of daylight regime on diurnal locomotor activity patterns of the European hare (Lepus europaeus) during summer. Mammalian Biology 77(6): 434-440. DOI: 10.1016/j.mambio.2012.07.004

Schmidt K. 1999. Variation in daily activity of the free-living Eurasian lynx (Lynx lynx) in Białowieża Primeval Forest, Poland. Journal of Zoology 249(4): 417-425. DOI: 10.1111/j.1469-7998.1999.tb01211.x

Schoener T.W. 1971. Theory of feeding strategies. Annual Review of Ecology and Systematics 2: 369-404. DOI: 10.1146/annurev.es.02.110171.002101

Seganfreddo S., Bertolini F., Vezzaro S., Vendramin A., Romani T., Madinelli A., Pesaro S., Filacorda S. 2017. Integration of activity sensor, GPS monitoring and phototrapping to describe brown bear (Ursus arctos) behaviour in the Eastern Alps. In: XXVII Convegno Nazionale della Società Italiana di Etologia (Calci, 18-21 June 2017). Calci. P. 7.

Seryodkin I.V., Kostyria A.V., Goodrich J.M., Miquelle D.G. 2013. Daily activity patterns of brown bear (Ursus arctos) of the Sikhote-Alin mountain range (Primorskiy Krai, Russia). Russian Journal of Ecology 44(1): 50 55. DOI: 10.1134/S1067413613010104

Sidorchuk N.V., Rozhnov V.V. 2010. European badger in Darwin reserve. Traditional and new methods in studying of ecology and behavior of denning predators. Moscow: KMK Scientific Press Ltd. 122 p. [In Russian]

Sidorchuk N.V., Volchenko A.E., Rozhnov V.V. 2014. Daily activity of the European badger (Meles meles Linnaeus,
1758) (Mustelidae, Mammalia) at settlements in several populations of European Russia. Povolzhsky Ecological Journal 4: 601-610. [In Russian]

Sidorchuk N.V., Rozhnov V.V., Maslov M.V. 2016. Daily activity of Asian badger (Meles leucurus amurensis Schrenck 1859) settlements in Ussuriisky Reserve. Scientific Notes of Petrozavodsk State University 2(155): 42-48. [In Russian]

Sokolov V.E., Kuznetsov G.V. 1978. Daily rhythms activity of mammalian. Cytological and ecological aspects. Moscow: Nauka. 264 p. [In Russian]

Soutyrina S.V., Riley M.D., Goodrich J.M., Seryodkin I.V., Miquelle D.G. 2013. A population estimate of Amur tiger using camera traps. Vladivostok: Dalnauka. $156 \mathrm{p}$.

Stelmock J.J., Dean F.C. 1986. Brown bear activity and habitat use in Denali national park - 1980. In: Sixth International Conference on Bear Research and Management (Grand Canyon, Arizona, USA, February 1983). Vol. 6. International Association of Bear Research and Management. P. 155-167. DOI: 10.2307/3872820

TEAM Network. 2011. Terrestrial vertebrate (camera trap) monitoring protocol implementation manual. Tropical Ecology Assessment and Monitoring Network. Virginia, USA: Centre for Applied Biodiversity Science. 69 p.

Weckel M., Giuliano W., Silver S. 2006. Jaguar (Panthera onca) feeding ecology: distribution of predator and prey through time and space. Journal of Zoology 270(1): 2530. DOI: 10.1111/j.1469-7998.2006.00106.x

Worton B.J. 1989. Kernel methods for estimating the utilization distribution in home-range studies. Ecology 70(1): 164-168. DOI: 10.2307/1938423

Yamazaki K., Kozakai C., Kasai S., Goto Yu., Koike S., Furubayashi K. 2008. A preliminary evaluation of activitysensing GPS collars for estimating daily activity patterns of Japanese black bears. Ursus 19(2): 154-161. DOI: 10.2192/07GR009.1

Zaccaroni M., Biliotti N., Buccianti A., Calieri S., Ferretti M., Genghini M., Riga F., Trocchi V., Dessì-Fulgheri F. 2013. Winter locomotor activity patterns of European hares (Lepus europaeus). Mammalian Biology 78(6): 482-485. DOI: 10.1016/j.mambio.2013.07.001

Zar J. 2010. Biostatistical analysis. New Jersey: Pearson Prentice Hall. 944 p.

Zaumyslova O.Yu., Bondarchuk S.N. 2017. Assessment of the Long-tailed Goral (Naemorhedus caudatus: Bovidae) population status in the Sikhote-Alin Reserve using camera-traps. Nature Conservation Research 2(Suppl. 1): 151-163. DOI: 10.24189/ncr.2017.024 [In Russian] Zheltukhin A.S. 1987. Lynx of the southern taiga of the Upper Volga (ecology, behavior, issues of management and protection). $\mathrm{PhD}$ thesis abstract. Moscow. 15 p. [In Russian]

Zoller H., Drygala F. 2013. Activity patterns of the invasive raccoon dog (Nyctereutes procyonoides) in North East Germany. Folia Zoologica 62(4): 290-296. DOI: 10.25225/fozo.v62.i4.a6.2013 


\title{
СУТОЧНАЯ АКТИВНОСТЬ КРУПНЫХ И СРЕДНИХ МЛЕКОПИТАЮЩИХ ПО ДАННЫМ ФОТОЛОВУШЕК В ЦЕНТРАЛЬНО-ЛЕСНОМ ЗАПОВЕДНИКЕ (ВАЛДАЙСКАЯ ВОЗВЫШЕННОСТЬ, РОССИЯ)
}

\author{
С. С. Огурцов ${ }^{1}$, А. С. Желтухин ${ }^{1}$, И. П. Котлов ${ }^{2}$ \\ ${ }^{1}$ Центрально-Лесной государственный природный биосферный заповедник, Россия \\ ${ }^{2}$ Институт проблем экологии и эволючии имени А.Н. Северцова РАН, Россия \\ e-mail:etundra@mail.ru,azheltukhin@mail.ru,ikotlov@gmail.com
}

\begin{abstract}
На примере трех средних (заяц-беляк (Lepus timidus), енотовидная собака (Nyctereutes procyonoides), европейский барсук (Meles meles)) и пяти крупных (лось (Alces alces), кабан (Sus scrofa), волк (Canis lupus), рысь (Lynx lynx), бурый медведь (Ursus arctos)) видов млекопитающих рассмотрены результаты анализа суточной активности, полученные по данным фотоловушек в Центрально-Лесном заповеднике (Тверская область, Россия). За период 2010-2017 гг. отработано 30158 фотоловушко-суток на 21 локации. Большинство рассмотренных млекопитающих проявляли активность в ночные и сумеречные часы (71\% всех кадров). Заяц-беляк был активен больше всего в ночное время суток (69\% регистраций). Енотовидная собака обладала полифазным типом активности преимущественно ночной формы, которая во многом была похожа на активность зайца-беляка. В отличие от зайца, енотовидная собака имела слабый пик в дневное время (25\%) и была чуть менее активна ночью (64\%). Барсук представил в нашем случае классический пример монофазной ночной активности. Его перемещения были приурочены к ночному (69\%) и сумеречному времени суток (20\%). У таких крупных копытных, как лось и кабан, доля ночной активности была схожей и составила около 45\% от всех регистраций. Отличие между ними заключалось в том, что лось имел бо́льшую сумеречную активность (29\%), чем кабан (20\%). У рыси и медведя были схожие суточные динамики регистраций: примерно 40\% их встреч приходилось на светлое время суток и $35 \%$ - на темное. Суммарная доля сумеречных часов активности рыси оказалась немного больше (25\%), чем у медведя (22\%), но достоверно они не различались. У медведя было максимальное число регистраций в дневное время среди всех остальных видов (44\%). Несмотря на то, что основным объектом питания рыси на территории заповедника является заяц-беляк, значительного перекрывания их суточных активностей не наблюдалось $\left(\widehat{\Delta}_{4}=0.75\right)$. В группе крупных хищников заметно выделялся волк, больше половины регистраций которого приходилось на ночное время (54\%), а треть - на дневное. В суточных регистрациях волка и лося отмечена тесная взаимосвязь. Активности этих видов значительно перекрывались друг с другом $\left(\widehat{\Delta}_{4}=0.89\right)$. Представлены сезонные изменения суточной активности каждого вида. По результатам факторного анализа все млекопитающие разделены на три обособленные группы. Первая группа включала в себя виды со склонностью к ночной активности (волк, лось, заяц-беляк, барсук и енотовидная собака), вторая группа - животных с полифазной активностью сумеречного типа (медведь и рысь). В третьей группе оказался только кабан, активность которого была приурочена к вечерним часам. Данная работа представляет собой первое продолжительное и непрерывное исследование с помощью фотоловушек в России, в рамках которого детально рассмотрены ритмы суточной активности нескольких средних и крупных млекопитающих.
\end{abstract}

Ключевые слова: бесконтактные методы, крупные хищники, ритмы активности, суточная активность, фотоловушки, Центрально-Лесной заповедник 